Article

\title{
New Analogs of Polyamine Toxins from Spiders and Wasps: Liquid Phase Fragment Synthesis and Evaluation of Antiproliferative Activity
}

\author{
Christos Vassileiou ${ }^{1}$, Stefania Kalantzi ${ }^{1}$, Eleanna Vachlioti ${ }^{1}$, Constantinos M. Athanassopoulos ${ }^{1, *(D)}$,

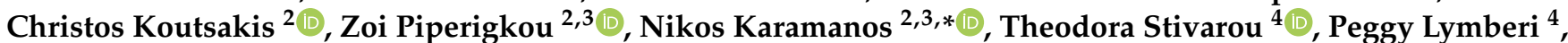 \\ Konstantinos Avgoustakis ${ }^{5}$ and Dionissios Papaioannou 1,*D
}

Citation: Vassileiou, C.; Kalantzi, S.; Vachlioti, E.; Athanassopoulos, C.M.; Koutsakis, C.; Piperigkou, Z.;

Karamanos, N.; Stivarou, T.; Lymberi, P.; Avgoustakis, K.; et al. New Analogs of Polyamine Toxins from Spiders and Wasps: Liquid Phase Fragment Synthesis and Evaluation of Antiproliferative Activity. Molecules 2022, 27, 447. https:// doi.org/10.3390/molecules27020447

Academic Editor: Andrea Bencini

Received: 11 December 2021

Accepted: 4 January 2022

Published: 10 January 2022

Publisher's Note: MDPI stays neutral with regard to jurisdictional claims in published maps and institutional affiliations.

Copyright: (C) 2022 by the authors. Licensee MDPI, Basel, Switzerland. This article is an open access article distributed under the terms and conditions of the Creative Commons Attribution (CC BY) license (https:// creativecommons.org/licenses/by/ $4.0 /)$.
1 Laboratory of Synthetic Organic Chemistry, Department of Chemistry, University of Patras, 26504 Patras, Greece; c.vassileiou@gmail.com (C.V.); s.kalantzi8@gmail.com (S.K.); eleannavah@yahoo.gr (E.V.)

2 Biochemical Analysis \& Matrix Pathobiology Research Group, Laboratory of Biochemistry, Department of Chemistry, University of Patras, 26504 Patras, Greece; ckoutsakis@upatras.gr (C.K.); zoipip@upatras.gr (Z.P.)

3 Foundation for Research and Technology-Hellas (FORTH)/Institute of Chemical Engineering Sciences (ICE-HT), 26110 Patras, Greece

4 Immunology Laboratory, Department of Immunology, Hellenic Pasteur Institute, 127 Vas. Sofias Avenue, Ampelokipi, 11521 Athens, Greece; tstivarou@pasteur.gr (T.S.); plymberi@pasteur.gr (P.L.)

5 Department of Pharmacy, University of Patras, 26504 Patras, Greece; avgoust@upatras.gr

* Correspondence: kath@upatras.gr (C.M.A.); N.K.Karamanos@upatras.gr (N.K.); dapapaio@upatras.gr (D.P.); Tel.: +30-2610997909 (C.M.A.); +30-2610997915 (N.K.); +30-2610962954 (D.P.)

\begin{abstract}
Polyamine toxins (PATs) are conjugates of polyamines (PAs) with lipophilic carboxylic acids, which have been recently shown to present antiproliferative activity. Ten analogs of the spider PATs Agel 416, HO-416b, and JSTX-3 and the wasp PAT PhTX-433 were synthesized with changes in the lipophilic head group and/or the PA chain, and their antiproliferative activity was evaluated on MCF-7 and MDA-MB-231 breast cancer cells, using Agel 416 and HO-416b as reference compounds. All five analogs of PhTX-433 were of very low activity on both cell lines, whereas the two analogs of JSTX-3 were highly active only on the MCF-7 cell line with $\mathrm{IC}_{50}$ values of $2.63-2.81 \mu \mathrm{M}$. Of the remaining three Agel 416 or HO-416b analogs, only the one with the spermidine chain was highly active on both cells with $\mathrm{IC}_{50}$ values of 3.15-12.6 $\mu \mathrm{M}$. The two most potent compounds in this series, Agel 416 and HO-416b, with $\mathrm{IC}_{50}$ values of $0.09-3.98 \mu \mathrm{M}$ for both cell lines, were found to have a very weak cytotoxic effect on the MCF-12A normal breast cells. The present study points out that the structure of both the head group and the PA chain determine the strength of the antiproliferative activity of PATs and their selectivity towards different cells.
\end{abstract}

Keywords: polyamine toxins; polyamines; lipophilic head groups; hydroxy amino acids; (indol3-yl)acetic acid; propargylglycine; 4-(3-trifluoromethyldiazirin-3-yl)benzoic acid; antiproliferative activity; breast cancer cells; cytotoxicity

\section{Introduction}

Polyamine toxins (PATs) are conjugates of polyamines (PAs) with lipophilic acids isolated from spider or wasp venoms (Figure 1). PATs are primarily investigated for their ability to block ionotropic glutamate receptors (iGluR) and thus constitute interesting drug targets for neurological and psychiatric disorders [1-4]. Recent studies showed that the PATs are also endowed with interesting antiproliferative activity, which seems to depend on the structure of the lipophilic head group (PATs $\mathrm{PA}_{366}$ and $\mathrm{PA}_{389}$ from spider venom), with $\mathrm{PA}_{366}$ being significantly more active than $\mathrm{PA}_{389}$ in MCF-7 breast cancer cells. Both PATs incorporate the spermine (Spm, a 3-4-3 PA) chain and either a 4-hydroxyphenyl ( $\left.\mathrm{PA}_{366}\right)$ or $1 \mathrm{H}$-indol-3-yl subgroup $\left(\mathrm{PA}_{389}\right)$ in the head group [5]. Potential protein targets involved 
in tumor development and breast cancer were identified for these PATs [5]. On the other hand, the antiproliferative activity seems to depend on the structure of the PA chain (PATs Agel 416 and HO-416b also from spider venom), with PAT HO-416b being $c a$ six times more active than PAT Agel 416 in the estrogen receptor alpha (ER $\alpha)$-positive MCF-7 breast cancer cell line with low metastatic potential, but slightly less active in the ER $\beta$-positive MDA-MB-231 highly invasive breast cancer cell line [6]. PATs Agel 416 and HO-416b differ only in the arrangement of their amino functions in the PA chain, the former being a 3-3-4-3 PA and the latter a 4-3-3-3 PA. It should be noted that a plethora of PA analogs with changes in the basic skeleton of naturally occurring PAs, suitable for SAR studies, has been synthesized and evaluated for their ability to inhibit the proliferation of cancer cells. These studies showed that the antiproliferative activity of this class of compounds depends on the number of the nitrogen atoms in the chain, the distance between the nitrogen atoms, the nature of the terminal alkyl substituents, and the charge these molecules can bear at physiological $\mathrm{pH}$ [2,7-9].
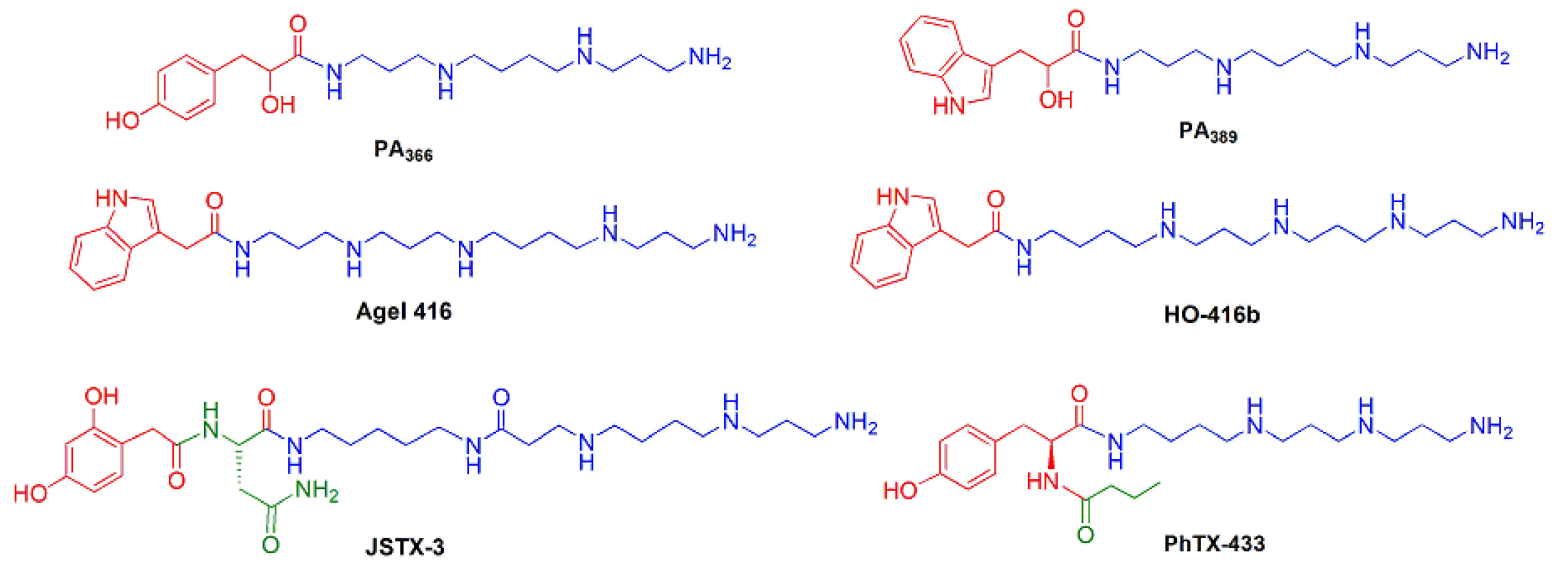

Figure 1. Structures of natural PATs from spider and wasp venoms related to the present work.

We now wish to report our results on the synthesis and antiproliferative activity in the two breast cancer cell lines MCF-7 and MDA-MB-231, of (a) shorter PA chain analogs (1-3, Figure 2) of PATs Agel 416 and HO-416b, (b) analogs of PhTX-433 with changes in the lipophilic head group (compounds 4 and 5) or the PA chain (compounds 6-8), and (c) analogs (compounds 9 and 10) of PAT JSTX-3, isolated from spider venoms, incorporating photoactivatable and clickable moieties [10] in the lipophilic part and the naturally occurring thermospermine (Tsm, a 3-3-4 PA) as the PA chain in the place of the longer PA chain of JSTX-3. With analogs 1-3, we aimed to study the effect of the PA chain length and the number of the amino functions on the established strong antiproliferative effect of PATs Agel 416 and HO-416b, whereas with analogs 4-8, we wished to study the effect of the structures of the lipophilic head group and of the PA chain on the potential antiproliferative effect of PAT PhTX-433. It should be noted that the synthetic analog 6, commonly abbreviated as PhTX-343, has been used as a reference compound for SAR studies instead of the natural PAT PhTX-433 [11]. Finally, bisamide analogs 9 and 10, bearing in the lipophilic head group a combination of an aromatic carboxylic acid with a photo-labeling moiety (a diazirine ring) and an amino acid with a clickable moiety (a terminal alkyne function), were designed in such a way that in the case they also presented comparable antiproliferative activity with the natural PATs or analogs thereof, they could be used at a later stage for the identification of the potential target(s) of their antiproliferative activity. They could also provide evidence of the possible effect of the site of attachment of the lipophilic head group in an asymmetric PA molecule, such as Tsm, on the antiproliferative activity. 


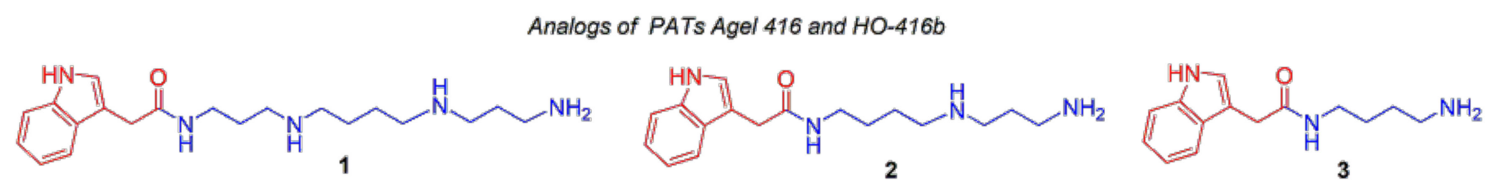

Analogs of PAT PhTX-433<smiles>CCCC(=O)NC(C(=O)NCCCCNCCCNCCCN)[C@H](C)O</smiles><smiles>CCCCNC(=O)[C@@H](NC(=O)C(O)O)[C@H](C)O</smiles><smiles>CCC(=O)NC(Cc1ccc(O)cc1)C(=O)NCCCNCCCNCCCN</smiles><smiles>CCCCNCCCCNCCCCN</smiles><smiles>CCCCNC(=O)C(Cc1ccc(O)cc1)NC(=O)CCCCNCCCNCCCN</smiles>

Analogs of PAT JSTX-3<smiles>C#CC[C@H](NC(=O)c1ccc(C2(C(F)(F)F)N=N2)cc1)C(=O)NCCCCNCCCNCCCN</smiles><smiles>C#CCC(NC(=O)c1ccc(C2(C(F)(F)F)N=NN2)cc1)C(=O)NCCCNCCCNCCCN</smiles>

Figure 2. Structures of synthesized PAT analogs in the context of the present study.

\section{Results and Discussion}

\subsection{Chemistry}

A variety of chemical strategies have been developed, both in liquid and solid phases, for the synthesis of PAs, analogs, and conjugates thereof [2,12]. Quite recently, a general approach for the liquid-phase fragment synthesis of orthogonally protected PAs and their application to the synthesis of the PATs Agel 416 and HO-416b has been reported [13]. This particular methodology, with minor modifications, was also applied for the synthesis of the PAT analogs 1-10 described in the present work, which involved the assembly of the required PA skeleta orthogonally protected at their amino functions so that selective deprotection of the desired terminal amino functionality would allow the attachment of the appropriate lipophilic head group on that particular position of the PA chain.

\subsubsection{The Selectively Protected PA Skeleta}

Key intermediates for the assembly of conjugates 1-10 are the selectively protected PAs 11-13, 15-18, and 20 (Figure 3). From the latter, compounds 11, 12, and 16-18 were available in our laboratory from a previous project [13] whereas compounds $\mathbf{1 3}, \mathbf{1 5}$, and 20 were synthesized as depicted in Figure 3 using compounds 12, 14, and 19 as starting materials [13], respectively. In particular, intermediate 13 was prepared from the spermidine (Spd, a 3-4 PA) derivative 12 through a two-step sequence in 54\% yield for the two steps [13]. It involved the selective removal of the Phth-protecting group via hydrazinolysis at refluxing $\mathrm{EtOH}$ and then nosylation of the deprotected primary amino group with $o$-nitrophenylsulphonyl chloride (nosyl chloride, $\mathrm{NsCl}$ ) in dichloromethane (DCM) in the presence of $\mathrm{Et}_{3} \mathrm{~N}$. 


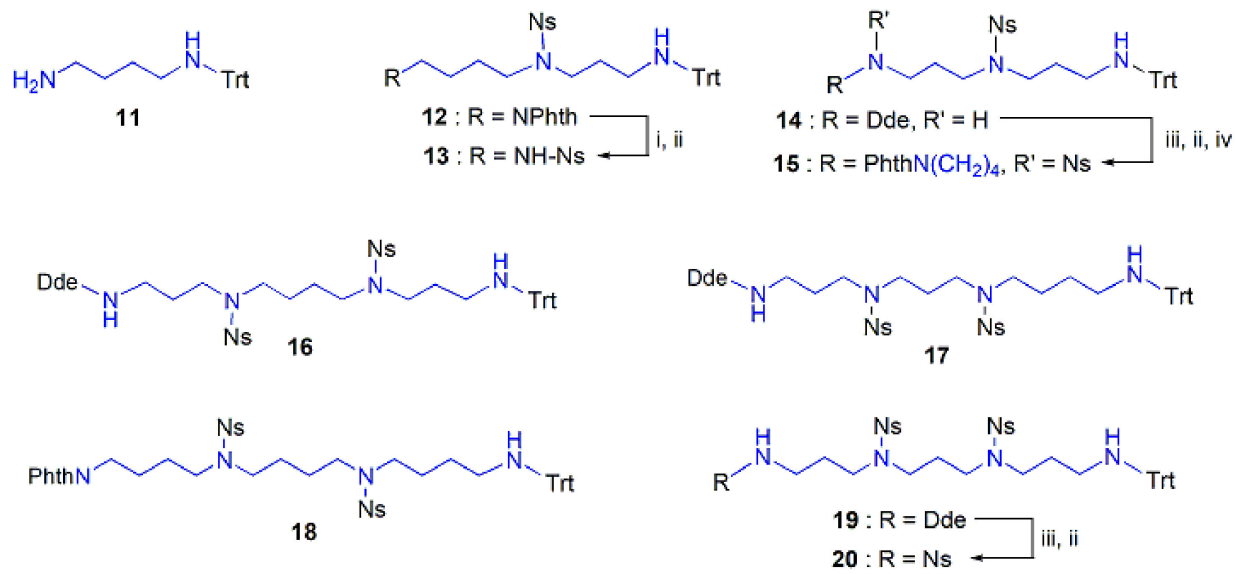

Figure 3. Structures of selectively protected PAs. Reagents and conditions: (i) $\mathrm{H}_{2} \mathrm{NNH}_{2} \cdot \mathrm{H}_{2} \mathrm{O}, \mathrm{EtOH}$, $78{ }^{\circ} \mathrm{C}, 2 \mathrm{~h}, 87 \%$; (ii) $\mathrm{NsCl}, \mathrm{Et}_{3} \mathrm{~N}, \mathrm{DCM}, 0{ }^{\circ} \mathrm{C}, 2 \mathrm{~h}$ then $25^{\circ} \mathrm{C}, 2 \mathrm{~h}, 62-81 \%$; (iii) $2 \% \mathrm{Et}_{2} \mathrm{NH}$ in DMF, $25^{\circ} \mathrm{C}$, $30 \mathrm{~min}, 72-94 \%$; (iv) PhthN $\left(\mathrm{CH}_{2}\right)_{4} \mathrm{Br}, \mathrm{K}_{2} \mathrm{CO}_{3}, \mathrm{DMF}, 60{ }^{\circ} \mathrm{C}, 2.5 \mathrm{~h}, 80 \%$.

On the other hand, compound $\mathbf{1 5}$ was synthesized from the norspermidine (Nsd, a 3-3 PA) derivative 14 through a three-step sequence, which involved hydrazine-mediated removal of the 1-(4,4-dimethyl-2,6-dioxocyclohexylidene)ethyl (Dde)-protecting group, followed by nosylation of the resulting primary amino function. Finally, alkylation of the nosylated amino functionality with $\mathrm{N}$-(4-bromobutyl)phthalimide in the presence of $\mathrm{K}_{2} \mathrm{CO}_{3}$ produced compound 15 in $39 \%$ overall yield. The $N$-(4-bromobutyl)phthalimide was obtained in $90 \%$ from $\mathrm{N}$-(4-hydroxybutyl)phthalimide [13] using the Appel reaction (see Experimental Section). The conversion of the orthogonally protected nonspermine (Nsm, a 3-3-3 PA) derivative 19 to the trinosylated Nsm intermediate 20 was performed in two steps with $76 \%$ overall yield, which involved Dde group removal followed by nosylation of the liberated primary amino function [13].

\subsubsection{The Lipophilic Head Groups}

The lipophilic head groups of the synthesized PAT analogs 1-10 were attached to the PA chains using either commercially available building blocks, such as compounds 21

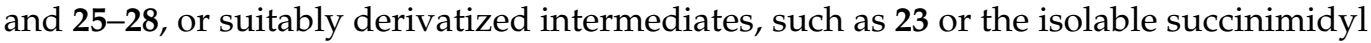
'active' ester 29 (Figure 4). Compound 23 was prepared from carboxylic acid 22 [13] in 80\% yield in an analogous manner to that described for its homologous compound 24 [13]. On the other hand, 'active' ester $\mathbf{2 9}$, a commercially available but very expensive compound (CAS 87736-89-8), was readily prepared for the needs of the present work in $91 \%$ yield through the condensation of acid $\mathbf{2 8}$ and $\mathrm{N}$-hydroxysuccinimide (HOSu) in the presence of the coupling agent $N, N^{\prime}$-dicyclohexylcarbodiimide (DCC).

\subsubsection{Assembly of the Conjugates}

\section{Shorter PA Chain Analogs 1-3 of PATs Agel 416 and HO-416b}

The synthesis of Agel 416 analog 1 (Scheme 1), incorporating the Spm chain, initially involved the condensation of the dinosylated spermidine (Spd, a 3-4 PA) derivative 13 with alcohol 23 under Mitsunobu reaction conditions providing the fully protected Spm conjugate 30 in $48 \%$ yield. Then, selective denosylation of the secondary amino functions of $\mathbf{3 0}$ was performed using sodium thiophenolate providing the new intermediate $\mathbf{3 1}$ in $61 \%$ yield. Finally, both the tert-botuxycarbonyl (Boc) and the triphenylmethyl (trityl, Trt)-protecting groups were removed upon trifluoroacetic acid (TFA)-mediated acidolysis yielding Agel 416 analogue 1, isolated as its corresponding tetratrifluoroacetate salt, in $53 \%$ yield.

On the other hand, the synthesis of HO-416b analog 2, incorporating the Spd chain, initially involved the removal of the phthalyl (Phth)-protecting group from the orthogonally protected Spd derivative 12 [13], through hydrazinolysis in refluxing ethanol, yielding the 
selectively deprotected Spd derivative 32 in $87 \%$ yield. The primary amino function of compound 32 was then acylated with (indol-3-yl)acetic acid (21), which had been previously activated with the coupling agent DCC in the presence of the coupling auxiliary HOSu. That way, the intermediate 33 was obtained in $65 \%$ yield. Treatment of the latter with sodium thiophenolate in DMF resulted in the selective deprotection of the secondary amino function yielding the new intermediate 34 in $46 \%$ yield. Finally, acidolysis of the Trt aminoprotecting group with 10\% TFA in DCM, in the presence of PhSH serving as carbocation scavenger, provided the PAT analog 2 in $55 \%$ yield.

The synthesis of HO-416b analog 3, incorporating the putrescine (Put, a 4 PA) chain, initially involved the acylation of the monotritylated Put derivative $\mathbf{1 1}$ with acid 21, which had been previously activated with DCC and HOSu, yielding the intermediate 35 in 75\% yield. Then, acidolysis of the Trt amino-protecting group with 10\% TFA in DCM, in the presence of $\mathrm{PhSH}$, provided the PAT analog 3 in $67 \%$ yield.

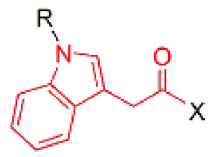

21: $\mathrm{R}=\mathrm{H}, \mathrm{X}=\mathrm{OH}$

22: $\mathrm{R}=\mathrm{Boc}, \mathrm{X}=\mathrm{OH}$

$24: \mathrm{R}=\mathrm{BOC}, \mathrm{X}=\mathrm{NH}\left(\mathrm{CH}_{2}\right)_{4} \mathrm{OH}$

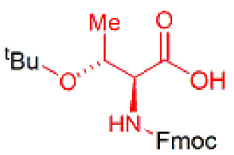

25

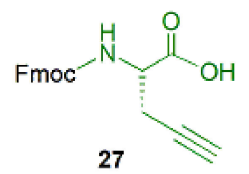

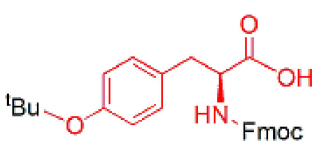

26

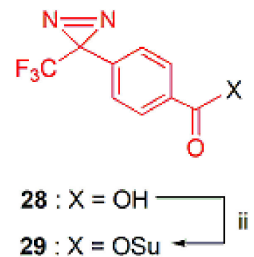

Figure 4. Structures of compounds suitable for the attachment of the lipophilic head groups to the PA chains. Reagents and conditions: (i) HOSu/DCC, DMF, $0{ }^{\circ} \mathrm{C}, 30 \mathrm{~min}$ then $25^{\circ} \mathrm{C}, 2 \mathrm{~h}$, followed by addition of $\mathrm{H}_{2} \mathrm{~N}\left(\mathrm{CH}_{2}\right)_{3} \mathrm{OH}, 25{ }^{\circ} \mathrm{C}, 10 \mathrm{~min}, 80 \%$; (ii) $\mathrm{HOSu} / \mathrm{DCC}, \mathrm{THF}, 0{ }^{\circ} \mathrm{C}, 30 \mathrm{~min}$ then $25^{\circ} \mathrm{C}$, $2 \mathrm{~h}, 87 \%$.

PAT Analogs $\mathbf{4}$ and 9-10 Incorporating the Tsm Chain

The synthesis of the PhTX-433 analog 4, in which the aromatic amino acid L-tyrosine (L-Tyr) has been replaced by the aliphatic amino acid L-threonine (L-Thr), is outlined in Scheme 2.

It starts from the orthogonally protected Tsm derivative 15, whose synthesis has been described above (Figure 3). Compound 15, upon hydrazinolysis, yielded the selectively protected Tsm derivative 36 in $71 \%$ yield. This was then coupled with the commercially available Fmoc-L-Thr $\left({ }^{\mathrm{t}} \mathrm{Bu}\right)-\mathrm{OH}(25)$ in the presence of the coupling agent 2-(1H-benzotriazol-1-yl)-1,1,3,3-tetramethyluronium hexafluorophosphate (HBTU) and ethyldiisopropylamine (DIPEA) in DMF yielding the conjugate 37 in $81 \%$ yield. Removal of the 9-fluorenylmethoxycarbonyl (Fmoc)-protecting group from the amino acid residue took place with $25 \%$ diethylamine in DCM yielding the partially protected conjugate 38 , which upon coupling with butanoic acid, also in the presence of the coupling agents HBTU and DIPEA, yielded bisamide 39 in $48 \%$ yield for the two last steps. Treatment of intermediate 39 with sodium thiophenolate in DMF resulted in the removal of the nosyl-protecting groups yielding the partially protected PAT analog 40 in $51 \%$ yield. Finally, both the tertbutyl ( ${ }^{\mathrm{t}} \mathrm{Bu}$ ) and the Trt-protecting groups were removed on treatment with $50 \%$ TFA in $\mathrm{DCM}$, in the presence of $\mathrm{PhSH}$, yielding the PAT analog 4, in the form of its corresponding tritrifluoroacetate salt, in $89 \%$ yield. 

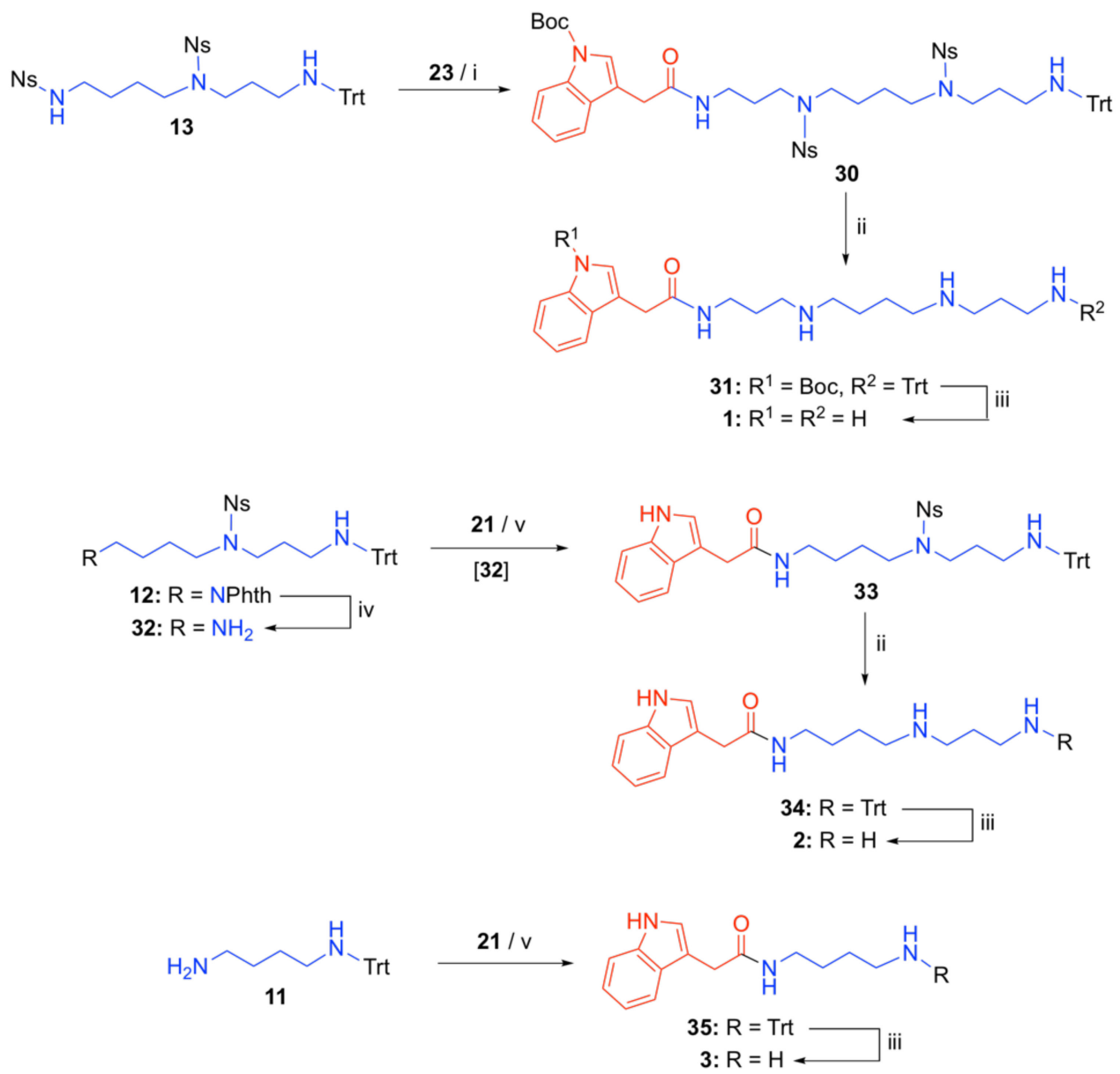

Scheme 1. Outline of synthetic routes to shorter PA chain analogs 1-3 of the PATs Agel 416 and HO-416b. Reagents and conditions: (i) $\mathrm{Ph}_{3} \mathrm{P} /{ }^{\mathrm{i}} \mathrm{PrO}_{2} \mathrm{CN}=\mathrm{NCO}_{2}{ }^{\mathrm{i} P r}, \mathrm{THF}, 0{ }^{\circ} \mathrm{C}, 15 \mathrm{~min}$ then $25^{\circ} \mathrm{C}, 2 \mathrm{~h}$, 48\%; (ii) $\mathrm{PhSH} / \mathrm{Na}_{2} \mathrm{CO}_{3}, \mathrm{DMF}, 25{ }^{\circ} \mathrm{C}, 12 \mathrm{~h}, 46-61 \%$; (iii) $10 \%$ TFA in $\mathrm{CH}_{2} \mathrm{Cl}_{2}, \mathrm{PhSH}, 25{ }^{\circ} \mathrm{C}, 1 \mathrm{~h}$, 53-67\%; (iv) $\mathrm{H}_{2} \mathrm{NNH}_{2} \cdot \mathrm{H}_{2} \mathrm{O}, \mathrm{EtOH}, 80^{\circ} \mathrm{C}, 2 \mathrm{~h}, 87 \%$; (v) (a) DCC $\mathrm{HOSu}, \mathrm{DMF}, 0{ }^{\circ} \mathrm{C}, 30 \mathrm{~min}$ then $25^{\circ} \mathrm{C}$, $2 \mathrm{~h}$, (b) $\mathrm{Et}_{3} \mathrm{~N}, 25^{\circ} \mathrm{C}, 2 \mathrm{~h}, 65-75 \%$.

On the other hand, the synthesis of the regioisomeric PAT analogs 9 and 10, incorporating an amino acid and a lipophilic head group at N-12 and the N-1 positions, respectively, of the Tsm skeleton, is outlined in Scheme 3. Both syntheses have a common starting material, namely the orthogonally protected Tsm derivative 17 [13]. Treatment of compound 17 with $10 \%$ TFA in DCM resulted in the selective removal of the Trt-protecting group yielding the partially protected Tsm derivative 41, whereas treatment of the same compound with $2 \%$ $\mathrm{H}_{2} \mathrm{NNH}_{2} \cdot \mathrm{H}_{2} \mathrm{O}$ in DMF resulted in the removal of the Dde-protecting group providing the alternative partially protected Tsm derivative 42 in 79\% yield. Tsm derivatives 41 and 42 are key intermediates in the assembly of the skeleton of PAT analogs 9 and 10, respectively.

Thus, coupling of compounds $\mathbf{4 1}$ or $\mathbf{4 2}$ with the commercially available $N$-Fmocprotected amino acid (S)-propargylglycine in the presence of the coupling agent bromotripyrrolidinophosphonium hexafluorophosphate (PyBrOP) and DIPEA in DMF produced the corresponding amides 43 and 49 in 70\% and 76\% yields, respectively, for the two steps (detritylation and coupling). Removal of the Fmoc-protecting group from these compounds with $20 \% \mathrm{Et}_{2} \mathrm{NH}$ in DCM produced the corresponding partially protected conjugates 44 and 50, respectively. Each one of these conjugates were then acylated by the succinimidyl 'active' ester 29 in the presence of DIPEA in DMF to give bisamides 45 and 51 in $71 \%$ and $74 \%$ yield for the last two steps, respectively. In compound 45, we first proceeded with the replacement of the Dde-protecting group by the highly lipophilic Trt group, which facilitates aqueous work-up procedures and purifications with FCC chro- 
matography [13], as follows. Treatment of bisamide 45 with $2 \% \mathrm{H}_{2} \mathrm{NNH}_{2} \cdot \mathrm{H}_{2} \mathrm{O}$ in DMF produced the intermediate 46 in $73 \%$, which was then tritylated with $\mathrm{TrtCl}_{\text {and }} \mathrm{Et}_{3} \mathrm{~N}$ in DCM to give the new intermediate 47 . Finally, the Ns-protecting groups were removed from the intermediates $\mathbf{4 7}$ and $\mathbf{5 1}$ upon treatment with sodium thiophenolate in DMF, yielding the N-tritylated intermediates 48 and 52 in $75 \%$ and $92 \%$ yield, respectively, for the two steps (tritylation and denosylation). From these compounds, the projected PAT analogs 9 and 10 were obtained as the corresponding tritrifluoroacetate salts in $65 \%$ and $87 \%$ yield, respectively, upon TFA-mediated acidolysis.

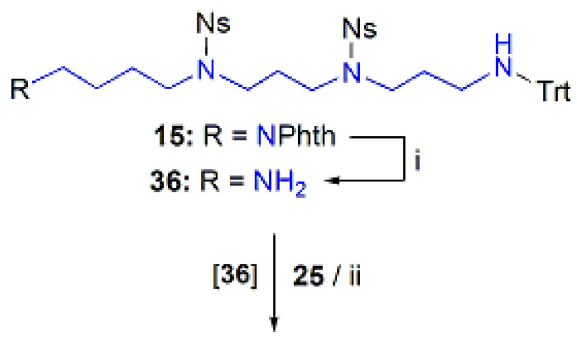

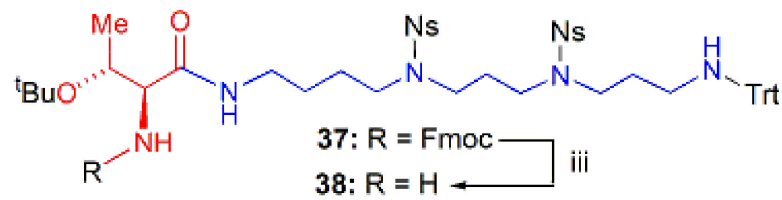

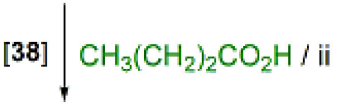

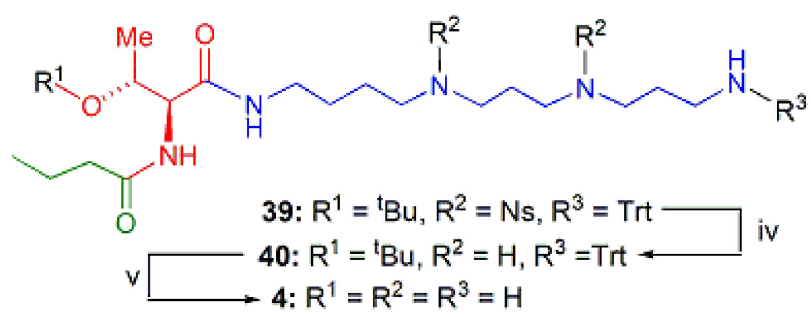

Scheme 2. Outline of synthetic route to PAT analog 10. Reagents and conditions: (i) $\mathrm{H}_{2} \mathrm{NNH}_{2} \cdot \mathrm{H}_{2} \mathrm{O}$, $\mathrm{EtOH}, 80^{\circ} \mathrm{C}, 1 \mathrm{~h}, 71 \%$; (ii) $\mathrm{HBTU},{ }^{\mathrm{i}} \mathrm{Pr}_{2} \mathrm{NEt}, \mathrm{DMF}, 0{ }^{\circ} \mathrm{C}, 5 \mathrm{~min}$ then $25^{\circ} \mathrm{C}, 30 \mathrm{~min}, 61-81 \%$; (iii) $25 \%$ $\mathrm{Et}_{2} \mathrm{NH}$ in $\mathrm{CH}_{2} \mathrm{Cl}_{2}, 25^{\circ} \mathrm{C}, 1 \mathrm{~h}, 78 \%$; (iv) $\mathrm{PhSH} / \mathrm{Na}_{2} \mathrm{CO}_{3}, \mathrm{DMF}, 25^{\circ} \mathrm{C}, 12 \mathrm{~h}, 51 \%$; (v) 50\% TFA in $\mathrm{CH}_{2} \mathrm{Cl}_{2}, \mathrm{PhSH}, 25^{\circ} \mathrm{C}, 1 \mathrm{~h}, 89 \%$.

PAT Analogs 5 and 6 Incorporating the Spm Chain

The synthesis of the PhTX-433 analog 5, in which the Tsm chain has been replaced by the Spm chain and the amino acid L-Tyr in the lipophilic head group has been replaced by L-Thr, is outlined in Scheme 4.

It started from the orthogonally protected Spm derivative 16 [13]. Compound 16, upon the selective removal of the Dde-group with $2 \% \mathrm{H}_{2} \mathrm{NNH}_{2} \cdot \mathrm{H}_{2} \mathrm{O}$ in $\mathrm{DMF}$, yielded the selectively protected Spm derivative 53 in 91\% yield. This was then coupled with the commercially available Fmoc-L-Thr $\left({ }^{\mathrm{t}} \mathrm{Bu}\right)-\mathrm{OH}(25)$ in the presence of the coupling agent HBTU and DIPEA, yielding the conjugate 54 in 78\% yield. Removal of the Fmoc-protecting group from the amino acid residue took place with $25 \%$ diethylamine in DCM, yielding the partially protected conjugate 55 in $90 \%$ yield, which upon coupling with butanoic acid, also in the presence of HBTU and DIPEA, yielded the bisamide 56 in 57\% yield. Treatment of intermediate 56 with sodium thiophenolate in DMF resulted in the removal of the nosyl-protecting groups yielding the partially protected intermediate 57. Finally, the ${ }^{t} \mathrm{Bu}$ - and the Trt-protecting groups were removed upon treatment with $50 \%$ TFA in $\mathrm{DCM}$, in the presence of $\mathrm{PhSH}$, yielding the PAT analog 5, in the form of its corresponding tritrifluoroacetate salt, in $87 \%$ yield for the last two steps. 
The synthesis of the PhTX-433 analog 6, in which the Tsm chain has been replaced by the Spm chain, is also outlined in Scheme 4. It started from the partially protected Spm derivative 53. Coupling of this compound with the commercially available FmocL-Tyr $\left({ }^{\mathrm{t}} \mathrm{Bu}\right)-\mathrm{OH}(\mathbf{2 6})$ in the presence of the coupling agent HBTU and DIPEA yielded the conjugate 58. Removal of the Fmoc-protecting group from the amino acid residue took place with $25 \%$ diethylamine in DCM, yielding the partially protected conjugate 59 , which upon coupling with butanoic acid, also in the presence of HBTU and DIPEA, provided the bisamide $\mathbf{6 0}$ in $64 \%$ yield for the last three steps. Treatment of intermediate $\mathbf{6 0}$ with sodium thiophenolate in DMF resulted in the removal of the nosyl-protecting groups yielding the intermediate $\mathbf{6 1}$ in $65 \%$ yield. Finally, the ${ }^{\mathrm{t}} \mathrm{Bu}$ - and the Trt-protecting groups were removed uon treatment with $50 \%$ TFA in DCM, also in the presence of PhSH, yielding the PhTX-433 analog 6, in the form of its corresponding tritrifluoroacetate salt, in $90 \%$ yield.

It should be noted that an extended array of PhTX-433 analogs, including PhTX-343, has been previously synthesized by several research groups, both in solution and solid phases, in order to be studied as antagonists of transmitter receptors [11,14-21].
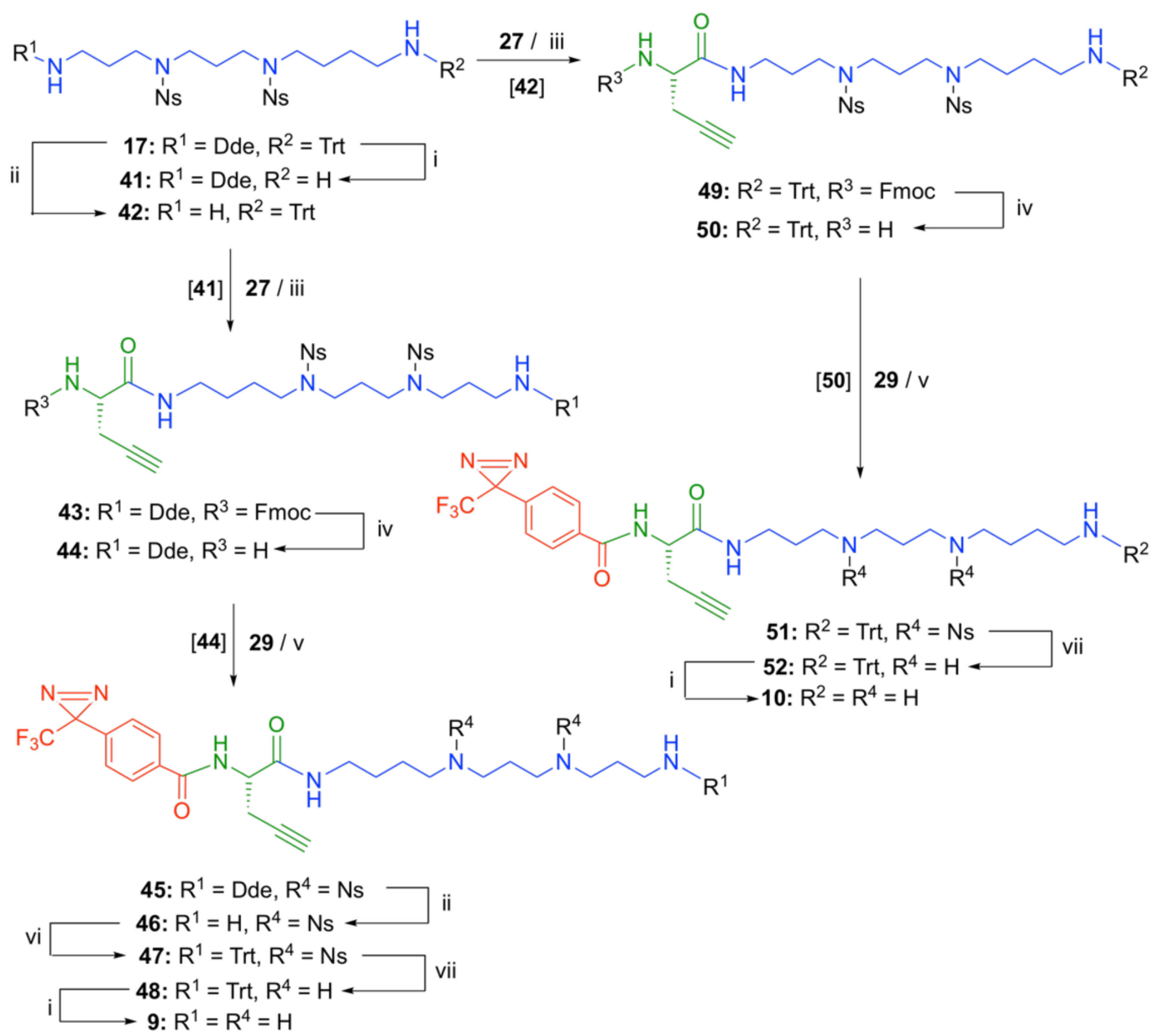

Scheme 3. Outline of synthetic routes to PAT analogs 9 and 10. Reagents and conditions: (i) 10\% TFA in $\mathrm{CH}_{2} \mathrm{Cl}_{2}, \mathrm{PhSH}, 25^{\circ} \mathrm{C}, 0.5-1 \mathrm{~h}, 65 \%$ (9) and $87 \%$ (10); (ii) $2 \% \mathrm{H}_{2} \mathrm{NNH}_{2} \cdot \mathrm{H}_{2} \mathrm{O}$ in DMF, $25^{\circ} \mathrm{C}, 30-90 \mathrm{~min}$, $79 \%$ (42) and 73\% (46); (iii) $\mathrm{PyBrOP},{ }^{\mathrm{i}} \mathrm{Pr}_{2} \mathrm{NEt}, \mathrm{DMF}, 0{ }^{\circ} \mathrm{C}, 5 \mathrm{~min}$ then $25^{\circ} \mathrm{C}, 30 \mathrm{~min}, 70 \%$ (43) and $76 \%$ (49); (iv) $25 \% \mathrm{Et}_{2} \mathrm{NH}$ in $\mathrm{CH}_{2} \mathrm{Cl}_{2}, 25^{\circ} \mathrm{C}, 1-3 \mathrm{~h}$; (v) ${ }^{\mathrm{i}} \mathrm{Pr}_{2} \mathrm{NEt}, \mathrm{DMF}, 25^{\circ} \mathrm{C}, 12 \mathrm{~h}, 71 \%$ (45) and $74 \%$ (51); (vi) $\mathrm{TrtCl}, \mathrm{Et}_{3} \mathrm{~N}, \mathrm{CH}_{2} \mathrm{Cl}_{2}, 25^{\circ} \mathrm{C}, 1 \mathrm{~h}$; (vii) $\mathrm{PhSH} / \mathrm{Na}_{2} \mathrm{CO}_{3}, \mathrm{DMF}, 25^{\circ} \mathrm{C}, 3-5 \mathrm{~h}, 75 \%$ (48) and $92 \%$ (52). 


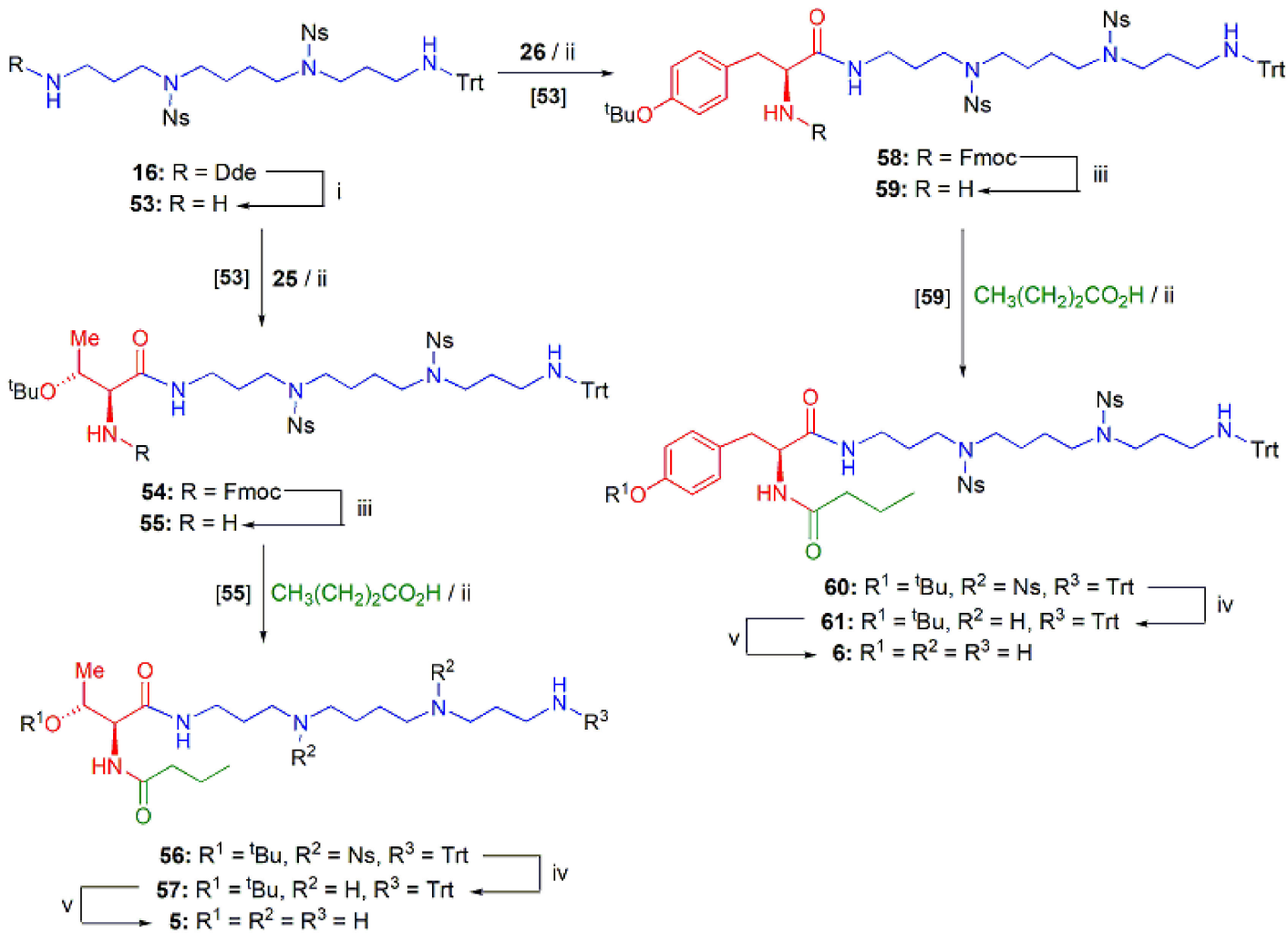

Scheme 4. Outline of synthetic routes to PAT analogues 5 and 6. Reagents and conditions: (i) $2 \%$ $\mathrm{H}_{2} \mathrm{NNH}_{2} \cdot \mathrm{H}_{2} \mathrm{O}$ in DMF, $25^{\circ} \mathrm{C}, 30 \mathrm{~min}, 91 \%$; (ii) $\mathrm{HBTU},{ }^{i} \mathrm{Pr}_{2} \mathrm{NEt}, \mathrm{DMF}, 0{ }^{\circ} \mathrm{C}, 5 \mathrm{~min}$ then $25^{\circ} \mathrm{C}, 30 \mathrm{~min}$, $78 \%$ (54), 57\% (62) and 64\% (56); (iii) $25 \% \mathrm{Et}_{2} \mathrm{NH}$ in $\mathrm{CH}_{2} \mathrm{Cl}_{2}, 25{ }^{\circ} \mathrm{C}, 1 \mathrm{~h}, 90 \%$ (55); (iv) $\mathrm{PhSH} / \mathrm{Na}_{2} \mathrm{CO}_{3}$, DMF, $25^{\circ} \mathrm{C}, 12 \mathrm{~h}, 72 \%$ (57) and 65\% (61); (v) 50\% TFA in $\mathrm{CH}_{2} \mathrm{Cl}_{2}, \mathrm{PhSH}, 25^{\circ} \mathrm{C}, 1 \mathrm{~h}, 87 \%$ (5) and $90 \%$ (9).

\section{Analogs 7 and 8 of PhTX-433 with Longer PA Chains}

The synthesis of the PhTX-433 analog 7, in which the Tsm chain has been replaced by the longer homospermine (Hsm, a 4-4-4 PA) chain, is outlined in Scheme 5. It started with the hydrazinolysis in refluxing ethanol of the orthogonally protected Hsm derivative 18 [13] yielding the partially protected Hsm derivative 62 in $41 \%$ yield. This was then coupled with the commercially available Fmoc-L-Tyr $\left({ }^{\mathrm{t}} \mathrm{Bu}\right)-\mathrm{OH}(\mathbf{2 6})$ in the presence of the coupling agent HBTU and DIPEA, yielding the conjugate 63 in 73\% yield.

Removal of the Fmoc-protecting group from the amino acid residue took place with $25 \%$ diethylamine in DCM yielding the partially protected conjugate 64 , which upon coupling with butanoic acid, also in the presence of HBTU and DIPEA, yielded the bisamide 65. Treatment of intermediate 65 with sodium thiophenolate in DMF resulted in the removal of the nosyl-protecting groups yielding the partially protected PhTX-433 analog 66 in 79\% overall yield for the last three steps. Finally, the ${ }^{t} \mathrm{Bu}$ - and the Trt-protecting groups were removed upon treatment with 50\% TFA in DCM, also in the presence of $\mathrm{PhSH}$, yielding the PhTX-433 analog 7, in the form of its corresponding tritrifluoroacetate salt, in $85 \%$ yield. 


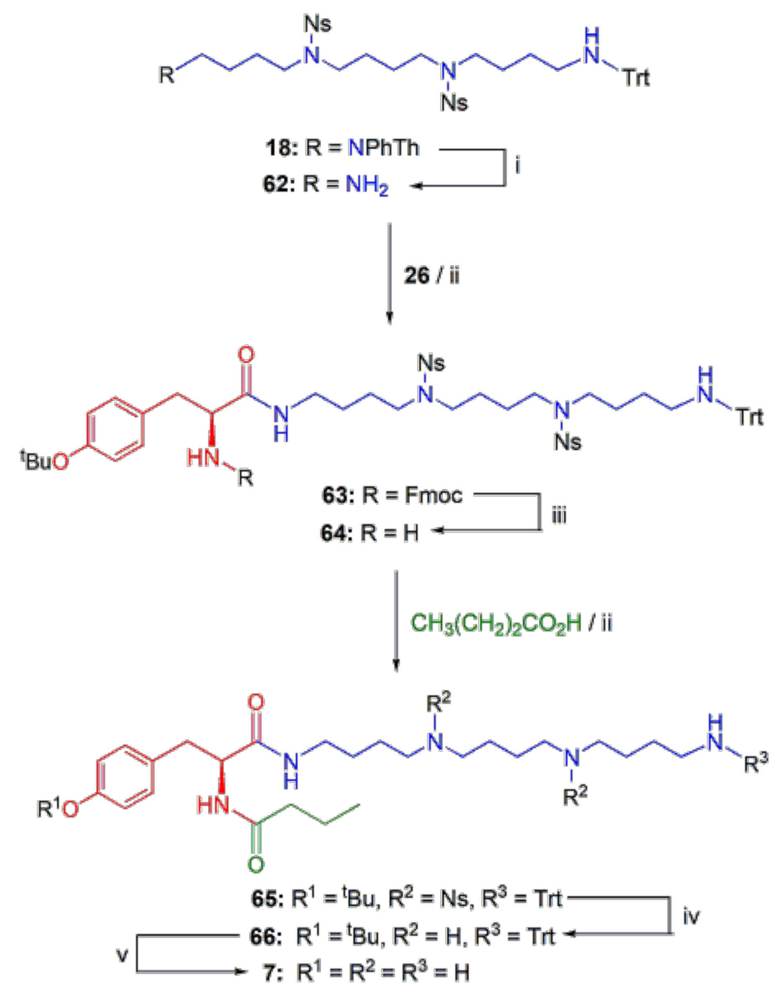

Scheme 5. Outline of synthetic route to PhTX-433 analog 7. Reagents and conditions: (i) $\mathrm{H}_{2} \mathrm{NNH}_{2} \cdot \mathrm{H}_{2} \mathrm{O}$, $\mathrm{EtOH}, 80{ }^{\circ} \mathrm{C}, 2 \mathrm{~h}, 41 \%$; (ii) $\mathrm{HBTU},{ }^{\mathrm{i}} \mathrm{Pr}_{2} \mathrm{NEt}, \mathrm{DMF}, 0{ }^{\circ} \mathrm{C}, 5 \mathrm{~min}$ then $25^{\circ} \mathrm{C}, 30 \mathrm{~min}, 73 \%$ (69); (iii) $25 \%$ $\mathrm{Et}_{2} \mathrm{NH}$ in $\mathrm{CH}_{2} \mathrm{Cl}_{2}, 25^{\circ} \mathrm{C}, 1 \mathrm{~h}$; (iv) PhSH $/ \mathrm{Na}_{2} \mathrm{CO}_{3}, \mathrm{DMF}, 25^{\circ} \mathrm{C}, 12 \mathrm{~h}, 79 \%$; (v) $50 \%$ TFA in $\mathrm{CH}_{2} \mathrm{Cl}_{2}$, $\mathrm{PhSH}, 25^{\circ} \mathrm{C}, 1 \mathrm{~h}, 85 \%$.

On the other hand, the synthesis of the PhTX-433 analog 8 , in which the Tsm chain has been replaced by the longer 3-3-3-4 PA chain, is outlined in Scheme 6. It started from the norspermine (Nsm, a 3-3-3 PA) derivative 20, whose preparation from the orthogonally protected Nsm derivative 19 [13] has been described above (Figure 3). It involved the alkylation of the primary nosylamide group of 20 with $\mathrm{PhthN}\left(\mathrm{CH}_{2}\right)_{4} \mathrm{Br}$ in DMF in the presence of $\mathrm{K}_{2} \mathrm{CO}_{3}$, yielding the orthogonally protected 3-3-3-4 PA derivative 67. Hydrazinolysis of phthalimide 67 [13] in refluxing ethanol yielded the partially protected 3-3-3-4 PA derivative 68 in $52 \%$ yield for the two steps. This was then coupled with the commercially available Fmoc-L-Tyr $\left({ }^{\mathrm{t}} \mathrm{Bu}\right)-\mathrm{OH}(\mathbf{2 6})$ in the presence of the coupling agent HBTU and DIPEA, yielding the conjugate 69 in $60 \%$ yield.

Removal of the Fmoc-protecting group from the amino acid residue took place with $25 \% \mathrm{Et}_{2} \mathrm{NH}$ in DCM, yielding the partially protected conjugate 70 , which upon coupling with butanoic acid in the presence of HBTU and DIPEA, yielded the bisamide 71. Treatment of intermediate $\mathbf{7 1}$ with sodium thiophenolate in DMF resulted in the removal of the nosylprotecting groups yielding the partially protected PhTX-433 analog 72 in $74 \%$ yield for the last three steps. Finally, the ${ }^{t} \mathrm{Bu}$ - and the Trt-protecting groups were removed upon treatment with 50\% TFA in DCM, in the presence of PhSH, yielding the PhTX-433 analog 8, in the form of its corresponding tetratrifluoroacetate salt, in $83 \%$ yield. 


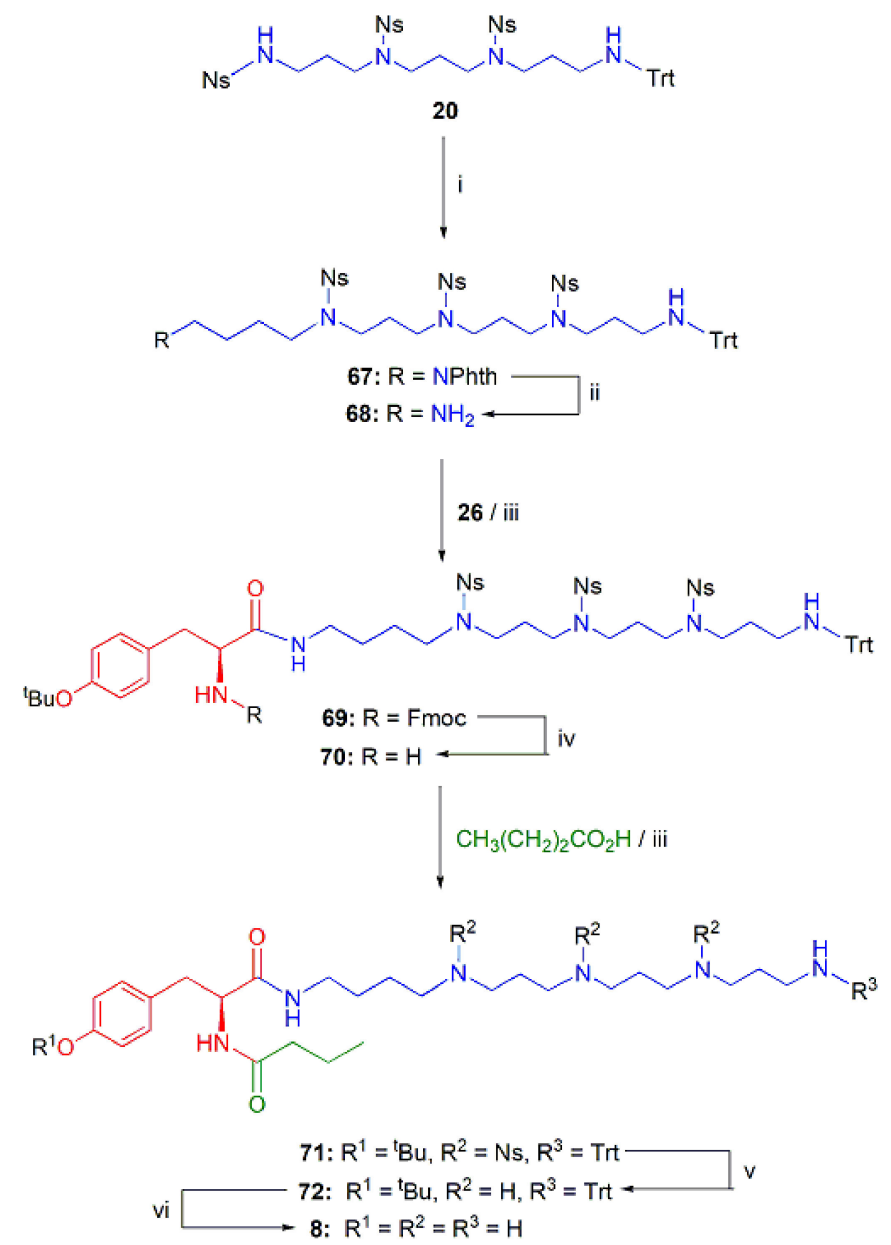

Scheme 6. Outline of synthetic route to PhTX-433 analog 8. Reagents and conditions: (i) $\mathrm{PhthN}\left(\mathrm{CH}_{2}\right)_{4} \mathrm{Br}$, $\mathrm{K}_{2} \mathrm{CO}_{3}, \mathrm{DMF}, 6{ }^{\circ} \mathrm{C}, 2.5 \mathrm{~h}$; (ii) $\mathrm{H}_{2} \mathrm{NNH}_{2} \cdot \mathrm{H}_{2} \mathrm{O}, \mathrm{EtOH}, 80^{\circ} \mathrm{C}, 1 \mathrm{~h}, 52 \%$; (iii) $\mathrm{HBTU},{ }^{i} \mathrm{Pr}_{2} \mathrm{NEt}, \mathrm{DMF}, 0^{\circ} \mathrm{C}$, $5 \mathrm{~min}$ then $25^{\circ} \mathrm{C}, 30 \mathrm{~min}, 60 \%$ (69); (iv) $25 \% \mathrm{Et}_{2} \mathrm{NH}$ in $\mathrm{CH}_{2} \mathrm{Cl}_{2}, 25^{\circ} \mathrm{C}, 1-2 \mathrm{~h}$; (v) $\mathrm{PhSH} / \mathrm{Na}_{2} \mathrm{CO}_{3}, \mathrm{DMF}$ $25^{\circ} \mathrm{C}, 12 \mathrm{~h}, 74 \%$; (vi) $50 \%$ TFA in $\mathrm{CH}_{2} \mathrm{Cl}_{2}, \mathrm{PhSH}, 25^{\circ} \mathrm{C}, 1 \mathrm{~h}, 83 \%$.

\subsection{Biological Evaluation}

\subsubsection{Antiproliferative Activity on Breast Cancer Cells}

The antiproliferative activity of the synthesized compounds was evaluated using MCF7 and MDA-MB-231 breast carcinoma cells. MCF-7 cells are characterized by epithelial morphology, low metastatic potential, and low aggressiveness, and are estrogen receptor alpha (ER $\alpha$ )-positive, whereas MDA-MB-231cells are characterized by mesenchymal morphology, high metastatic potential, and high aggressiveness, and are ER $\beta$-positive. The cells were treated for $24 \mathrm{~h}$ with compounds $\mathbf{1 - 1 0}$ in a range of concentrations, from 0 to 200 or $400 \mu \mathrm{M}$. In addition, the cells were treated with acid 21 alone and an equimolar mixture of acid 21 and Spd (the PA substructure of conjugate 2), to determine the effect of conjugation on the antiproliferative activity. The estimated $\mathrm{IC}_{50}$ values for these compounds are provided in Table 1 (see also Supplementary Material, Table S1). For the sake of comparison, the $\mathrm{IC}_{50}$ values of PATs HO-416b and Agel 416, determined previously [6], are included in Table 1. Calculated $\log \mathrm{D}$ values at $\mathrm{pH} 7.4$, the physiological $\mathrm{pH}$ of blood serum, using ChemAxon's Chemicalize platform are also included in Table 1. 
Table 1. Antiproliferative activity of synthesized PATs and analogs in the MCF-7 and MDA-MB-231 breast cancer cell lines. SD values are also provided for each $\mathrm{IC}_{50}$ value.

\begin{tabular}{cccc}
\hline & \multicolumn{2}{c}{ IC $_{\mathbf{5 0}}(\boldsymbol{\mu M})$} \\
\hline Compound & LogD $^{\mathbf{1}}$ & MCF-7 & MDA-MB-231 \\
\hline Agel 416 & -7.54 & $0.55 \pm 0.02$ & $3.31 \pm 0.08$ \\
HO-416b & -6.25 & $0.09 \pm 0.012$ & $3.98 \pm 0.064$ \\
$\mathbf{1}$ & -6.21 & $>200$ & $>200$ \\
$\mathbf{2}$ & -2.84 & $3.15 \pm 0.25$ & $12.6 \pm 0.57$ \\
$\mathbf{3}$ & -1.49 & $272.4 \pm 11.2$ & $107.2 \pm 10.7$ \\
$\mathbf{4}$ & -6.66 & $>400$ & $>400$ \\
$\mathbf{5}$ & -8.16 & $>400$ & $>400$ \\
$\mathbf{6}$ & -5.97 & $>400$ & $>400$ \\
$\mathbf{7}$ & -6.81 & $>400$ & $>400$ \\
$\mathbf{8}$ & -6.05 & $>400$ & $>400$ \\
$\mathbf{9}$ & -3.87 & $2.63 \pm 1.58$ & $>200$ \\
$\mathbf{1 0}$ & -5.34 & $2.81 \pm 1.64$ & $262.2 \pm 42$ \\
$\mathbf{2 1}$ & -0.96 & $365.9 \pm 73$ & $282.5 \pm 55$ \\
\hline $\mathbf{2 1}+$ Spd $[\mathbf{2 1}$ Spd $=1: 1]$ & & $145.6 \pm 96$ & \\
\hline
\end{tabular}

${ }^{1}$ LogD values were calculated using ChemAxon's Chemicalize platform on 27 December 2021; https:// chemicalize.com (accessed on 3 January 2022).

\subsubsection{Cytotoxicity}

The cytotoxity of the two most potent antiproliferative agents in this series of compounds, namely PATs Agel 416 and HO-416b, was studied using the normal epithelial mammary cells MCF-12A, and the results are presented in Figure 5 (see also Supplementary Material, Figure S1). The $\mathrm{IC}_{50}$ values of the tested compounds are summarized in Table 2 (see also Supplementary Material, Table S2).

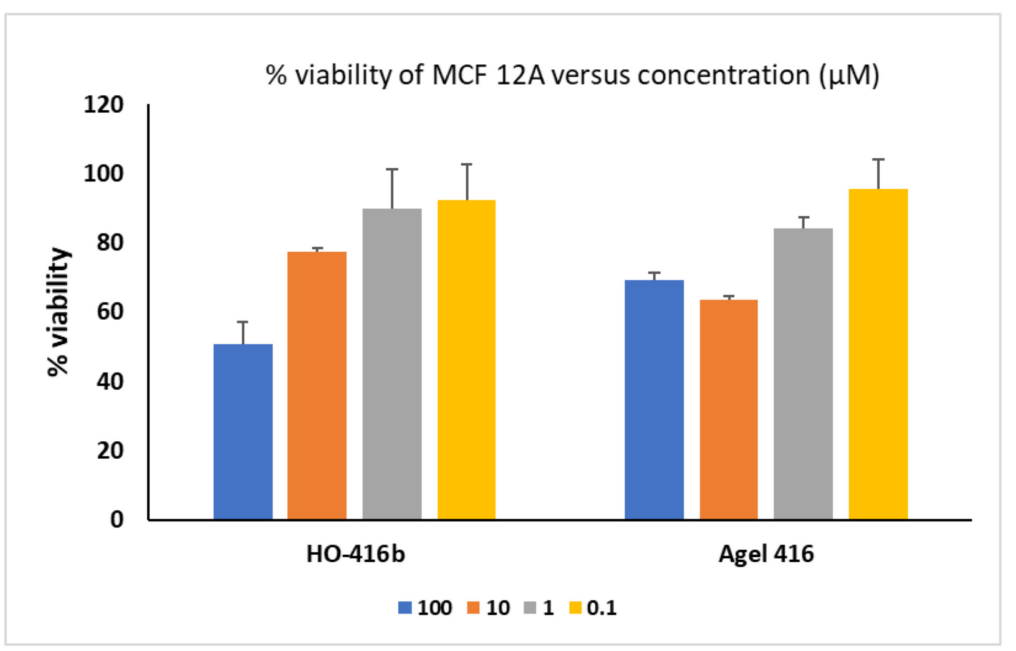

Figure 5. Viability of MCF-12A cells following treatments with PATs HO-416b and Agel 416.

Table 2. The $\mathrm{IC}_{50}$ values of PATs HO-416b and Agel 416 in MCF-12A normal epithelial mammary cells.

\begin{tabular}{cc}
\hline Compound & IC $_{50}(\mu \mathrm{M})$ \\
\hline Agel 416 & 184.14 \\
HO-416b & 97.24 \\
\hline
\end{tabular}




\subsubsection{Structure-Activity Relationships}

Antiproliferative Activity on the MCF-7 Cells

The synthesized PATs and analogs can be divided into three subgroups according to the lipophilic head group they are incorporating. The first subgroup consisted of spider toxins Agel 416 and HO-416b and analogs thereof and is characterized by the presence of the indole nucleus as the head-group attached to a PA skeleton of variable length and number of nitrogen atoms. The two most potent compounds in this cohort are the PATs HO-416b and Agel 416, with $\mathrm{IC}_{50}$ values of 0.09 and $0.55 \mu \mathrm{M}$, incorporating either the 4-3-3-3 or the 3-3-4-3 pentaamine skeleton with the former being ca 6 times more cytotoxic. From the other three PAT analogs, incorporating the common PAs Put (a 4 diamine), Spd (a 4-3 triamine), and Spm (a 3-4-3 tetraamine), the most potent compound was analog 2, incorporating Spd with an $\mathrm{IC}_{50}$ value of $3.15 \mu \mathrm{M}$. On the other hand, the analogues 1, incorporating the PA Spm, and 3, incorporating the PA Put, exhibited very low activity ( $\mathrm{IC}_{50}>200 \mu \mathrm{M}$ and $272 \mu \mathrm{M}$, respectively). Analog 2, sharing the 4-3 PA fragment of the most toxic PAT HO-416b, is 35 times less active than HO-416b. Therefore, we suggest that the pentaamine skeleton secures the highest possible activity followed by the 4-3 triamine skeleton provided by the PA Spd. Notably, (indol-3-yl)acetic acid (21) also had a very low antiproliferative activity $\left(\mathrm{IC}_{50}=365.9 \mu \mathrm{M}\right)$, which was improved $\left(\mathrm{IC}_{50}=145.6 \mu \mathrm{M}\right)$ when it was used in combination with an equimolar quantity of free Spd. It is apparent, however, that the conjugation of the two molecules created the PAT analog 2, which was significantly more active ( $c a 42$ times) than their mere combination.

The second subgroup involved analogs of PAT PhTX-433, isolated from wasps, with changes in the lipophilic head-group (analog 4) or the PA chain (analogs 6-8) or both (analog 5). However, all these PhTX-433 analogs had very low antiproliferative activity $\left(\mathrm{IC}_{50}>400 \mu \mathrm{M}\right)$, even the analog 8, which incorporated the 4-3-3-3 pentaamine skeleton seen in the very active PAT HO-416b. These results verify the importance of the structure of the head group on the antiproliferative activity of these compounds noticed earlier [5]. In that study, a 4-hydroxyphenyl ring in the lipophilic head group seems to be more important than an indole ring for the antiproliferative activity. However, concerning our compounds it seems that it is the indole ring of the head group that provides the highest activity (e.g., PAT HO-416b) and not the 4-hydroxyphenyl ring (e.g., PhTX-433 analog 8). Interestingly, by comparing the dose-dependent response (DDR) diagrams of these compounds it is evident that the 4-4-4 PA skeleton secures higher activity than the 4-3-3-3 PA skeleton and that replacement of the aromatic Tyr residue by the aliphatic Thr residue leads to higher activity when combined with the 4-3-3 PA (Tsm) skeleton.

The third subgroup includes the compounds $\mathbf{9}$ and $\mathbf{1 0}$ in which the lipophilic head group is attached to either the N1 or the N12 amino function of the natural PA Tsm. The lipophilic head group consisted of a phenyl ring, substituted at position 4 by the photoactivatable 3-trifluoromethyldiazirin-3-yl ring, connected to the Tsm tetraamine chain through the clickable amino acid $S$-propargylglycine. Interestingly, both compounds showed strong antiproliferative activity with $\mathrm{IC}_{50}$ values of 2.63 and $2.81 \mu \mathrm{M}$, respectively, which makes them interesting tools for identifying potential macromolecular targets responsible for their activity. It seems that the position of the attachment of the lipophilic group on the PA chain is not especially important as both 3-3-4 and 4-3-3 PA arrangements in the conjugates lead to comparable activity, with the latter being slightly more potent than the former.

It should be noted that the observed strength of the antiproliferative activity of PATs Agel 416 and HO-416b and the synthesized analogs 1-10 on the MCF-7 cells could not be correlated to their lipophilicity, a key property in drug action and safety [22]. For the present set of compounds, LogD is the preferred descriptor for lipophilicity due to the ionizable nature of their PA chains [22]. All compounds presented low lipophilicity ranging from -1.49 (analog 3 ) to -8.16 (analog 5). This is, of course, due to the fact that PAs at physiological $\mathrm{pH}$ exist in their corresponding polycationic form [2,23], and therefore it seems that the hydrophilicity of the PA chains surpasses the lipophilicity of the head groups, especially with the increase in the number of $\mathrm{N}$ atoms in the PA chain. From 
the five most active compounds, namely HO-416b, Agel 416, 9, 10, and 2, the first two are characterized by very low $\log D$ values $(-6.25$ and -7.54$)$ whereas the $\log D$ values from the remaining three analogs range from -2.84 to -5.34 . On the other hand, the least active analogs with tetraamine or pentaamine chains (analogs 1, 4, 5, and 6-8) are also characterized by very low $\log \mathrm{D}$ values ranging from -5.97 to -8.16 whereas analog 3 , with the shortest PA chain (Put) and the highest lipophilicity ( $\operatorname{LogD}-1.49)$, presented very low antiproliferative activity $(272 \mu \mathrm{M})$. However, the low lipophilicities of the PAs, PATs, and analogs do not hinder these molecules from passing the cellular membranes with the aid of polyamine uptake systems [23] and interacting effectively with their targets, such as nucleic acids, proteins, ion channels, and phospholipids [2]. It should be noted that the distance between the amino functionalities within a PA chain plays an important role in their recognition by the PA uptake systems [2]. In an attempt to correlate the lipophilicity of the head groups of the PATs and analogs to the observed antiproliferative activity, we calculated the $\log \mathrm{P}$ values, using the Chemicalize platform, of the neutral carboxylic acids $\mathrm{N}$-(4-(3-(trifluoromethyl)-3H-diazirin-3-yl)benzoyl)-L-propargylglycine $(\log \mathrm{P}=2.545), \mathrm{N}$ butanoyl-L-Tyr $(\log P=1.738)$, (indol-3-yl)acetic acid ( $\log \mathrm{P}=1.71)$, and $N$-butanoyl-L-Thr $(\log P-0.245)$. Although the lipophilicity of the head groups would then be correlated to the strong antiproliferative activity of Agel 416, HO-416b, and analogs 2, 9, and 10, compared for example to analogs 4 and 5, the correlation fails with analogs 6-8 whose lipophilic head group is of comparable lipophilicity to that of Agel 416, HO-416b, and analog $\mathbf{2}$. The same applies for analogs $\mathbf{1}$ and $\mathbf{3}$ bearing the (indol-3-yl)acetate head group.

\section{Antiproliferative Activity on the MDA-MB-231 Cells}

The two most potent compounds in the first subgroup are, again, the PATs HO-416b and Agel 416, with comparable $\mathrm{IC}_{50}$ values of 3.98 and $3.31 \mu \mathrm{M}$, incorporating either the 4-3-3-3 or the 3-3-4-3 pentaamine skeleton. Compared to Agel 416, which is only 6 times less cytotoxic to the MDA-MB-231 cells than the MCF-7 cells, HO-416b is ca 44 times less cytotoxic. From the other three PAT analogs, incorporating the PAs Put, Spd, and Spm, the most potent compound was, again, analog 2 incorporating the PA Spd with an $\mathrm{IC}_{50}$ value of $12.6 \mu \mathrm{M}$. The other two analogs with the PA Spm or Put skeleton were either of too low (analog 1, IC $50>200 \mu \mathrm{M}$ ) or low activity (analog 3, $\left.\mathrm{IC}_{50}=170.2 \mu \mathrm{M}\right)$. Analog 2 shares the 4-3 PA fragment of the toxic PAT HO-416b and is 4 times less active than HO-416b. Similarly, for the MDA-MB-231 cells, the pentaamine skeleton secures the highest possible activity followed by the 4-3 triamine skeleton provided by the PA Spd. It should be noted that the (indol-3-yl)acetic acid (21) alone had low antiproliferative activity $\left(\mathrm{IC}_{50}=262.2 \mu \mathrm{M}\right)$, which, in contrast to the MCF-7 cells, was not improved $\left(\mathrm{IC}_{50}=282.5 \mu \mathrm{M}\right)$ when it was used in combination with an equimolar quantity of free Spd. It is apparent here, too, that conjugation of the two molecules creating the PAT analog 2 had a significant effect on the antiproliferative activity ( $c a 22$ times more active) than their mere combination.

All analogs of PAT PhTX-433, consisting the second subgroup, had very low antiproliferative activity $\left(\mathrm{IC}_{50}>400 \mu \mathrm{M}\right)$, even analog 8 , which incorporates the 4-3-3-3 pentaamine skeleton seen in the very active PAT HO-416b. These results again verify the importance of the structure of the head group on the antiproliferative activity of these compounds noticed earlier [5] and that for the present cohort of compounds, the indole ring of the head group provides the highest activity (e.g., PATs HO-416b and Agel 416) and not the 4-hydroxyphenyl ring (e.g., PhTX-433 analog 8). Interestingly, by comparing the DDR diagrams of these compounds, it is evident that the 4-4-4 PA skeleton secures higher activity than the 4-3-3-3 PA skeleton and that replacement of the aromatic Tyr residue by the aliphatic Thr residue leads to higher activity when combined with the 4-3-3 PA skeleton.

Finally, both compounds $\mathbf{9}$ and $\mathbf{1 0}$ of the third subgroup showed low antiproliferative activity with $\mathrm{IC}_{50}>200 \mu \mathrm{M}$ and are the only compounds in the present series of compounds that show specificity for the MCF-7 cells. All other compounds showed either comparable activity for the two types of cells or a lack of significant activity for both types of cells. Furthermore, upon comparing the DDR diagrams of these two compounds it is evident 
that compound 10, in which the lipophilic head group is attached to the N1 position of the Tsm skeleton (a 3-3-4 PA arrangement), is slightly more active than compound 9, in which the lipophilic head-group is attached to position N12 of the Tsm skeleton (a 4-3-3 PA arrangement).

As it is the case with the MCF-7 cells, the observed strength of antiproliferative activity of PATs Agel 416 and HO-416b and the synthesized analogs 1-10 on the MDA-MB-231 cells could not be correlated to their lipophilicity. From the three most active compounds, namely HO-416b, Agel 416, and 2, the first two are characterized by very low LogD values ( -6.25 and -7.54$)$ whereas the $\log \mathrm{D}$ value for analog 2 was -2.84 . On the other hand, the least active analogs with tetraamine or pentaamine chains (analogs $\mathbf{1}$ and 4-10) are also characterized by low or very low LogD values ranging from -3.87 to -8.16 , whereas analog 3, with the shortest PA chain (Put) and the highest lipophilicity (LogD -1.49), presented very low antiproliferative activity $(107 \mu \mathrm{M})$.

\section{Cytotoxicity on MCF-12A Noncancerous Cells}

From the $\mathrm{IC}_{50}$ values given in Table 2, it is apparent that the two most potent antiproliferative compounds, namely PATs Agel 416 and HO-416b, are cytotoxic in normal mammary MCF-12A cells only in high concentrations and that $\mathbf{H O}-\mathbf{4 1 6} \mathbf{b}$ is $\mathrm{ca} 1.9$ times more cytotoxic than Agel 416. Taking into consideration these values and the $\mathrm{IC}_{50}$ values for the cytotoxicity of the compounds for the cancerous MCF-7 and MDA-MB-231 cells (Table 1), it is estimated that the selectivity index (SI) for PAT Agel 416 is ca 335 for the MCF-7 cells and $c a 56$ for the MDA-MB-231 cells. The corresponding values for PAT HO-416b are $c a$ 1080 and 24.

\section{Materials and Methods}

\subsection{General Information}

Melting points were determined with an Electrothermal apparatus and are uncorrected. ${ }^{1} \mathrm{H}-\mathrm{NMR}$ and ${ }^{13} \mathrm{C}-\mathrm{NMR}$ spectra were obtained at 600 and $150 \mathrm{MHz}$, respectively, on the Bruker AvanceIII HD spectrometer. Chemical shifts $(\delta)$ are reported for $\mathrm{CDCl}_{3}$ solutions in parts per million (ppm) downfield from tetramethylsilane (TMS), used as an internal standard, or for $\left(\mathrm{CD}_{3}\right)_{2} \mathrm{SO}$ solutions. Electron-spray ionization (ESI) mass spectra were recorded at $30 \mathrm{eV}$, on a Waters Micromass ZQ spectrometer using HPLC grade $\mathrm{MeOH}$ or $\mathrm{MeCN}$ as a solvent, or $\mathrm{MeCN} / \mathrm{H}_{2} \mathrm{O}$ as a solvent system. Elemental analyses for solid compounds were determined on a Carlo Erba EA 1108 CHNS elemental analyzer.

Analytical reversed-phase high-performance liquid chromatography (RP-HPLC) for compounds 1-3 was performed on an Agilent Technologies, 1260 Affinity, Quaternary Pump VL system equipped with a photodiode array detector. The purity of the final conjugates was determined using UV detection $(\lambda=254 \mathrm{~nm})$. The chromatographic method employed was the following: Column, LiChrosorb RP18 $(25 \mathrm{~cm} \times 4.6 \mathrm{~mm}, 5 \mu \mathrm{m})$; mobile phase I, $0.08 \%$ TFA in water; mobile phase II, acetonitrile with $0.08 \%$ TFA; flow rate, $1.0 \mathrm{~mL} / \mathrm{min}$; elution profile, gradient elution from 5 to $50 \%$ II over $30 \mathrm{~min}$. Analytical RP-HPLC for compounds $\mathbf{6 - 1 0}$ and the tetrabenzoylated derivatives of compounds $\mathbf{4}$ and 5 was performed on an Agilent Technologies 1100 system. The purity of the conjugates was determined using UV detection $(\lambda=220 \mathrm{~nm})$. The chromatographic method employed was the following: Column, Luna C18 $(100 \times 4.6 \mathrm{~mm}, 3 \mu \mathrm{m})$; temperature, $40^{\circ} \mathrm{C}$; flow rate, $1.25 \mathrm{~mL} / \mathrm{min}$; elution time, $7 \mathrm{~min}$; elution profile, gradient elution as shown in Table 3. 
Table 3. Gradient elution profile.

\begin{tabular}{cc}
\hline Time (min) & \% $\mathbf{M e C N} / \mathbf{H}_{\mathbf{2}} \mathbf{O}$ \\
\hline 0.00 & 7.0 \\
\hline 3.50 & 95.0 \\
\hline 6.00 & 95.0 \\
\hline 6.50 & 100.0 \\
\hline 7.00 & 7.0 \\
\hline
\end{tabular}

Compounds 4 and 5 were converted, prior to HPLC determination, to their corresponding tetrabenzoylated derivatives using a slight modification of the method described for the RP-HPLC determination of PAs [24]. Thus, to a solution of $5 \mu$ mole of conjugate 4 or 5 in $0.1 \mathrm{~mL} \mathrm{H}_{2} \mathrm{O}, 1 \mathrm{~mL}$ of $2 \mathrm{~N}$ aqueous $\mathrm{NaOH}$ and $5 \mu \mathrm{L}$ of benzoyl chloride were added, and the resulting solution was shaken for 3 min with the aid of a vortex mixer and then allowed to stand for $20 \mathrm{~min}$ at ambient temperature. An additional $5 \mu \mathrm{L}$ portion of benzoyl chloride was added, and shaking was repeated for $3 \mathrm{~min}$. Following $20 \mathrm{~min}$ of standing, the solution was diluted with $2 \mathrm{~mL}$ brine and extracted twice with $2 \mathrm{~mL}$ diethyl ether. The organic layers were combined, dried (anhydrous $\mathrm{Na}_{2} \mathrm{SO}_{4}$ ), and evaporated to dryness under reduced pressure. The residue was diluted in $0.5 \mathrm{~mL} \mathrm{H}_{2} \mathrm{O}$ and aliquots examined with RP-HPLC. The retention times and the ESI-MS spectra for these derivatives were as follows: Tetrabenzoylated $4\left(\mathrm{C}_{46} \mathrm{H}_{55} \mathrm{~N}_{5} \mathrm{O}_{7}\right.$, exact mass: 789.41$)$ : RP-HPLC: $t_{\mathrm{R}}=4.128 \mathrm{~min}$; MS (ESI, $30 \mathrm{eV}): \mathrm{m} / z$ 812.72 [M+Na] ${ }^{+}, 790.76[\mathrm{M}+\mathrm{H}]^{+}$. Tetrabenzoylated $5\left(\mathrm{C}_{46} \mathrm{H}_{55} \mathrm{~N}_{5} \mathrm{O}_{7}\right.$, exact mass: 789.41): RP-HPLC: $t_{\mathrm{R}}=4.160 \mathrm{~min}$; MS (ESI, $\left.30 \mathrm{eV}\right): \mathrm{m} / z 812.79[\mathrm{M}+\mathrm{Na}]^{+}, 790.76$ $[\mathrm{M}+\mathrm{H}]^{+}$. All synthesized PAT analogs (compounds 1-10) subjected to biological evaluation were $>95 \%$ pure by RP-HPLC.

Flash column chromatography (FCC) was performed on Acros Organics silica gel $0.035-0.070 \mathrm{~mm}, 60 \AA$, and TLC on Merck silica gel $60 \mathrm{~F}_{254}$ films $(0.2 \mathrm{~mm})$ precoated on aluminum foil. Spots were visualized with UV light at $254 \mathrm{~nm}$ and by spraying with a ninhydrine solution ( $0.3 \mathrm{~g}$ ninhydrin, $3 \mathrm{~mL}$ gl. acetic acid, $97 \mathrm{~mL}$ 1-butanol). The solvent systems used for the development of TLC or FCC are the following: (A) $\mathrm{CHCl}_{3} / \mathrm{MeOH}$ (95:5), (B) $\mathrm{CHCl}_{3} / \mathrm{MeOH}$ (9:1), (C) $\mathrm{CHCl}_{3} / \mathrm{MeOH}$ (8:2), (D) $\mathrm{CHCl}_{3} / \mathrm{MeOH} /$ conc. $\mathrm{NH}_{3}$ (99:1:0.1), (E) $\mathrm{CHCl}_{3} / \mathrm{MeOH} /$ conc. $\mathrm{NH}_{3}$ (95:5:0.5), (F) $\mathrm{CHCl}_{3} / \mathrm{MeOH} /$ conc. $\mathrm{NH}_{3}$ (9:1:0.1), (G) $\mathrm{CHCl}_{3} / \mathrm{MeOH} /$ conc. $\mathrm{NH}_{3}$ (8:2:0.2), (H) $\mathrm{CHCl}_{3} / \mathrm{MeOH} /$ conc. $\mathrm{NH}_{3}$ (7:3:0.3), (I) $\mathrm{CHCl}_{3} /$ $\mathrm{MeOH} /$ conc. $\mathrm{NH}_{3}$ (6:4:0.4), (J) PhMe/EtOAc (95:5), (K) PhMe/EtOAc (9:1), (L) PhMe/EtOAc (8:2), (M) PhMe/EtOAc (7:3), (N) PhMe/EtOAc (6:4), (O) PhMe/EtOAc (1:1), (P) EtOAc/ $\mathrm{PhMe}(8: 2),(\mathrm{Q}) \mathrm{EtOAc} / \mathrm{PhMe}$ (7:3), (R) EtOAc (100\%).

All solvents were dried and/or purified according to standard procedures prior to use. Solvents were routinely removed at $c a 40^{\circ} \mathrm{C}$ under reduced pressure on Büchi Rotavapor RE 111 apparatus. Air-sensitive reagents were handled under inert atmosphere (Ar). All reagents employed in the present work were purchased from either Sigma-Aldrich or Alfa Aesar or Merck or Acros Organics and were used without further purification. DIAD was used in the context of this work as a commercially available safer alternative to DEAD. The photo-affinity labeling (PAL) reagent 4-(3-trifluoromethy-3H-diaziridin-3-1)benzoic acid (28) was purchased from TCI and the amino acid derivatives Fmoc-L-Thr $\left({ }^{\mathrm{t}} \mathrm{Bu}\right)-\mathrm{OH}(25)$, Fmoc-L-Tyr $\left({ }^{\mathrm{t}} \mathrm{Bu}\right)-\mathrm{OH}(\mathbf{2 6})$, and Fmoc-propargylglycine (27) were purchased from Bachem or Iris Biotech. Succinimidyl 4-(3-(trifluoromethyl)-3H-diazirin-3-yl)benzoate (29) (CAS 87736-89-8) is a commercially available, very expensive compound, which was prepared as described in the Supplementary Materials for the needs of the present work. The intermediates $N^{4}, N^{8}$-dinosyl-N ${ }^{1}$-tritylspermidine (13), $N^{4}$-nosyl- $N^{1}$-tritylnorspermidine, $N^{4}, N^{7}$ dinosyl- $N^{1}$-tritylnorspermidine, $N^{4}$-nosyl- $N^{1}$-tritylspermidine (32), and $N^{4}, N^{9}$-dinosyl$N^{1}$-tritylspermine (53), were synthesized, for the needs of the present work, according to procedures described in ref. [13]. Experimental details for the synthesis and character- 
ization of intermediates and final products (PAT analogs 1-10) of the present work are provided in the Supplementary Materials.

3.2. Biological Evaluation

3.2.1. Cell Cultures and Conditions

Breast Cancer Cells

MCF-7 and MDA-MB-231 breast cancer cell lines were purchased from the American Type Culture Collection (ATCC). All cells were routinely cultured in a humidified $95 \%$ air $/ 5 \% \mathrm{CO}_{2}$ incubator at $37^{\circ} \mathrm{C}$ in complete medium Dulbecco's Modified Eagle's Medium (DMEM) supplemented with 10\% $(v / v)$ fetal bovine serum (FBS) $1.0 \mathrm{mM}$ sodium pyruvate, $2 \mathrm{mM}$ l-glutamine, and $100 \mathrm{IU} / \mathrm{mL}$ penicillin. The synthesized compounds were dissolved in $\mathrm{ddH}_{2} \mathrm{O}$ (or DMSO for compound 27 and the equimolar mixture of compounds 27 and $\mathrm{Spd}$ ) at a final concentration of $10 \mathrm{mM}$ and further dilutions were conducted with culture medium.

\section{Determination of IC50 values}

MCF-7 and MDA-MB-231 breast cancer cells were seeded in 12-well plates and were allowed to grow up to $60-70 \%$ confluence. After renewing the culture medium, cancer cells were treated for $24 \mathrm{~h}$ in serum-containing culture medium with compounds 1-10 in a range of concentrations, from 0 to 200 or $400 \mu \mathrm{M}$. In addition, cells were treated with acid 21 alone and an equimolar mixture of acid 21 and Spd in order to determine the effect of conjugation on the antiproliferative activity. Then, the surviving breast cancer cells were measured, either manually (for compounds Agel 416, HO-416b, 1-3, 6-7) or by measuring the absorbance following an MTT assay (for compounds 4-5, 8-10, 21 and 21+Spd), as described below in detail. The percentage of live cells was plotted against the log values of compound concentrations, and a non-linear fit plot was used to estimate the $\mathrm{IC}_{50}$ value for each compound.

\section{Cytotoxicity Evaluation in Normal Mammary Cells}

Normal epithelial mammary cells MCF-12A were obtained from ATCC. The cells were cultured in DMEM-F12 containing 1\% Penicillin/Streptomycin solution, $7 \%$ equine serum, $30 \mathrm{ng} / \mathrm{mL}$ epidermal growth factor, $0.5 \mu \mathrm{g} / \mathrm{mL}$ hydrocortisone, $0.1 \mu \mathrm{g} / \mathrm{mL}$ cholera toxin, and $10 \mu \mathrm{g} / \mathrm{mL}$ insulin, and passaged twice a week. The chemical compounds were reconstituted in DMSO.

For the MTT [3-(4,5-dimethylthiazol-2-yl)-2,5-diphenyltetrazolium bromide] assay, cells were seeded in a 96-well plate (26.000 cells/well) for $48 \mathrm{~h}$. Then, after overnight starvation through serum deprivation, cells were incubated for $24 \mathrm{~h}$, with the chemical compounds at $100,10,1$, and $0.1 \mu \mathrm{M}$ concentrations in the MCF-12A culture medium deprived of serum. Next, MTT $(5 \mathrm{mg} / \mathrm{mL}$ in sterile PBS) was added in an amount of $10 \%$ in the culture media volume for 4 -h cell incubation at $37^{\circ} \mathrm{C}$. Subsequently, an MTT solubilization solution was added, in an amount equal to the original culture media volume (100 $\mu \mathrm{L} /$ well), and the formazan crystals were dissolved through thorough pipetting. The spectrophotometric measure of cells' viability was performed in a Tecan (SPARK) spectrophotometer at an absorbance wavelength of $570 \mathrm{~nm}$. Incubation with $\mathrm{H}_{2} \mathrm{O}_{2}$ was established as cytotoxicity positive control. The percentage of viability for each sample was calculated with respect to cells incubated with MCF-12A culture media (without serum) containing $2 \%$ DMSO (negative cytotoxicity control).

\section{Conclusions}

Using the recently reported general approach for the liquid-phase fragment synthesis of orthogonally protected naturally occurring PAs [13], a collection of orthogonally protected PAs was synthesized and subsequently successfully applied to prepare ten analogs of the naturally occurring PATs Agel 416, HO-416b, and JSTX-3, isolated from spider venoms, and PhTX-433, isolated from wasp venoms. The antiproliferative activity of the 
thus-synthesized conjugates was evaluated in MCF-7 and the MDA-MB-231 breast cancer cell lines, using the PATs Agel $\mathbf{4 1 6}$ and HO-416b as reference compounds.

PATs Agel-416, HO-416b, and analog 2 thereof, with Spd as the PA chain, presented potent antiproliferative activity for both cancerous cell lines with $\mathrm{IC}_{50}$ values ranging from 0.09-3.15 $\mu \mathrm{M}$ (MCF-7) and 3.31-12.6 $\mu \mathrm{M}$ (MDA-MB-231). Two other compounds, namely the JSTX-3 analogs 9 and 10, incorporating photoactivatable and clickable groups in their head group, were also potent inhibitors but only for the MCF-7 cell line $\left(\mathrm{IC}_{50}=2.63-2.81 \mu \mathrm{M}\right)$. All other analogs presented either low or very low antiproliferative activity.

The present study reveals that both the structure of the lipophilic head group and the polyamine chain are of significant importance for the strength of the antiproliferative potency of the PATs and their selectivity towards different types of cancerous cells. On the other hand, the potent antiproliferative activity of JSTX-3 analogs for the MCF-7 cells make them attractive tools for identifying potential cellular macromolecular targets, which will help design more potent PAT-based antiproliferative agents.

The two most potent antiproliferative agents, Agel 416 and HO-416b, in this cohort of compounds presented very low cytotoxicity, in the range of $97-184 \mu \mathrm{M}$, on the MCF-12A normal epithelial mammary cell line, with selectivity indexes (SI) in the ranges 335-1080 and 24-56 for the MCF-7 and the MDA-MB-231 cells, respectively. Therefore, both compounds, and especially HO-416b, can be safely used for further evaluation studies as potential PAT-based anticancer drugs.

Supplementary Materials: The following supporting information can be downloaded online, Copies of selected ${ }^{1} \mathrm{H}$ - and ${ }^{13} \mathrm{C}-\mathrm{NMR}$ spectra, Diagrams of dose-dependent responses (DDR) of the tested compounds on MCF-7 and MDA-MB-231 breast cancer cells, Experimental protocols, Figure S1: Viability of MCF-12A cells after treatment with PATs HO-416b and Agel 416, Table S1: Structures and antiproliferative activity ( $\mathrm{IC}_{50}$ values) for tested compounds, Table S2: Structures and $\mathrm{IC}_{50}$ values for the effect of PATs Agel 416 and HO-416b on the viability of MCF-12A cells.

Author Contributions: Conceptualization, D.P., N.K. and C.M.A.; synthesis and characterization of compounds, C.V., S.K., E.V. and C.M.A.; supervision of synthesis, C.M.A.; biological evaluation of compounds, C.K., Z.P., N.K., P.L., T.S. and K.A.; writing-original draft preparation, D.P., N.K. and C.M.A.; writing-review and editing D.P., N.K., C.M.A. and K.A.; preparation of Supplementary Materials, E.V., Z.P. and C.K. All authors have read and agreed to the published version of the manuscript.

Funding: This research received no external funding.

Institutional Review Board Statement: Not applicable.

Informed Consent Statement: Not applicable.

Data Availability Statement: Data not contained within this article can be found in the attached Supplementary Materials.

Acknowledgments: This publication has been financed by the Research Committee of the University of Patras to which we are grateful. We also wish to thank T. Tselios and G. Rassias, Chemistry Department, University of Patras, for the RP-HPLC chromatograms and D. Vachliotis and A.K. Andreopoulou, Laboratory of Instrumental Analysis, University of Patras, for the NMR spectra and the Elemental Analyses.

Conflicts of Interest: The authors declare no conflict of interest.

\section{References}

1. Schulz, S. The Chemistry of Spider Toxins and Spider Silk. Angew. Chem. Int. Ed. 1997, 36, 314-326. [CrossRef]

2. Karigiannis, G.; Papaioannou, D. Structure, Biological Activity and Synthesis of Polyamine Analogues and Conjugates. Eur. J. Org. Chem. 2000, 2000, 1841-1863. [CrossRef]

3. Hahn, F.; Schepers, U. Solid Phase Chemistry for the Directed Synthesis of Biologically Active Polyamine Analogs, Derivatives, and Conjugates. In Combinatorial Chemistry on Solid Supports; Bräse, S., Ed.; Springer: Berlin/Heidelberg, Germany, 2007; Volume 278, pp. 135-208. [CrossRef] 
4. Olsen, C.A.; Kristensen, A.S.; Strømgaard, K. Small Molecules from Spiders Used as Chemical Probes. Angew. Chem. Int. Ed. 2011, 50, 11296-11311. [CrossRef] [PubMed]

5. Wilson, D.; Boyle, G.M.; McIntyre, L.; Nolan, M.J.; Parsons, P.G.; Smith, J.J.; Tribolet, L.; Loukas, A.; Liddell, M.J.; Rash, L.D.; et al The Aromatic Head Group of Spider Toxin Polyamines Influences Toxicity to Cancer Cells. Toxins 2017, 9, 346. [CrossRef]

6. Kalantzi, S.; Piperigkou, Z.; Athanassopoulos, C.M.; Karamanos, N.K.; Ruonala, R.; Helariutta, Y.; Papaioannou, D. Liquid Phase Fragment Synthesis of Orthogonally Protected Polyamines and Spider Toxins with Potential Anticancer Activity. In Proceedings of the 12th AIMECS (Asian Federation of Medicinal Chemistry International Medicinal Chemistry Symposium), Instabul, Turkey, 8-11 September 2019; p. 141.

7. Prakash, N.J.; Bowlin, T.L.; Davis, G.F.; Sunkara, P.S.; Sjoerdsma, A. Antitumor activity of norspermidine, a structural homologue of the natural polyamine spermidine. Anticancer Res. 1988, 8, 563-568.

8. Porter, C.W.; Mc Manis, J.; Casero, R.A.; Bergeron, R.J. Relative abilities of bis(ethyl) derivatives of putrescine, spermidine, and spermine to regulate polyamine biosynthesis and inhibit L1210 leukemia cell growth. Cancer Res. 1987, 47, $2821-2825$.

9. Seiler, N. Thirty Years of Polyamine-Related Approaches to Cancer Therapy. Retrospect and Prospect. Part 2. Structural Analogues and Derivatives. Curr. Drug Targets 2003, 4, 565-585. [CrossRef]

10. MacKinnon, A.L.; Taunton, J. Target Identification by Diazirine Photo-Cross-Linking and Click Chemistry. Curr. Protoc. Chem. Biol. 2009, 1, 55-73. [CrossRef]

11. Nakanishi, K.; Choi, S.K.; Hwang, D.; Lerro, K.; Orlando, M.; Kalivretenos, A.G.; Eldefrawi, A.T.; Eldefrawi, M.E.; Usherwood, P.N.R. Bioorganic studies of transmitter receptors with philanthotoxin analogs. Pure Appl. Chem. 1994, 66, 671-678. [CrossRef]

12. Kuksa, V.; Buchan, R.; Lin, P.K.T. Synthesis of Polyamines, Their Derivatives, Analogues and Conjugates. Synthesis 2000, 2000, 1189-1207. [CrossRef]

13. Kalantzi, S.; Athanassopoulos, C.M.; Ruonala, R.; Helariutta, Y.; Papaioannou, D. General Approach for the Liquid-Phase Fragment Synthesis of Orthogonally Protected Naturally Occurring Polyamines and Applications Thereof. J. Org. Chem. 2019, 84, 15118-15130. [CrossRef]

14. Asami, T.; Kagechika, H.; Hashimoto, Y.; Shudo, K.; Miwa, A.; Kawai, N.; Nakajima, T. Acylpolyamines Mimic the Action of Joro Spider Toxin (Jstx) on Crustacean Muscle Glutamate Receptors. Biomed. Res. 1989, 10, 185-189. [CrossRef]

15. Blagbrough, I.S.; Bruce, M.; Bycroft, B.W.; Mather, A.J.; Usherwood, P.N.R. Invertebrate pharmacological assay of novel, potent glutamate receptor antagonists: Acylated spermines. Pestic. Sci. 1990, 30, 397-403. [CrossRef]

16. Blagbrough, I.; Brackley, P.T.; Bruce, M.; Bycroft, B.W.; Mather, A.J.; Millington, S.; Sudan, H.L.; Usherwood, P.N. Arthropod toxins as leads for novel insecticides: An assessment of polyamine amides as glutamate antagonists. Toxicon 1992, 30, 303-322. [CrossRef]

17. Benson, J.; Schürmann, F.; Kaufmann, L.; Gsell, L.; Piek, T. Inhibition of dipteran larval neuromuscular synaptic transmission by analogues of philanthotoxin-4.3.3: A structure-activity study. Comp. Biochem. Physiol. Part C Comp. Pharmacol. 1992, 102, 267-272. [CrossRef]

18. Goodnow, R.; Konno, K.; Niwa, M.; Kallimopoulos, T.; Bukownik, R.; Lenares, D.; Nakanishi, K. Synthesis of glutamate receptor antagonist philanthotoxin-433 (PhTX-433) and its analogs. Tetrahedron 1990, 46, 3267-3286. [CrossRef]

19. Strømgaard, K.; Brier, T.J.; Andersen, K.; Mellor, I.R.; Saghyan, A.; Tikhonov, D.; Usherwood, P.N.R.; Krogsgaard-Larsen, P.; Jaroszewski, J.W. Solid-Phase Synthesis and Biological Evaluation of a Combinatorial Library of Philanthotoxin Analogues. J. Med. Chem. 2000, 43, 4526-4533. [CrossRef]

20. Strømgaard, K.; Andersen, K.; Ruhland, T.; Krogsgaard-Larsen, P.; Jaroszewski, J.W. A Versatile Method for Solid-Phase Synthesis of Polyamines: Neuroactive Polyamine Toxins as Example. Synthesis 2001, 2001, 0877-0884. [CrossRef]

21. Kromann, H.; Krikstolaityte, S.; Andersen, A.J.; Andersen, K.; Krogsgaard-Larsen, P.; Jaroszewski, J.W.; Egebjerg, J.; Strømgaard, K. Solid-Phase Synthesis of Polyamine Toxin Analogues: Potent and Selective Antagonists of $\mathrm{Ca}^{2+}$ Permeable AMPA Receptors. J. Med. Chem. 2002, 45, 5745-5754. [CrossRef]

22. Tsopelas, F.; Giaginis, C.; Tsantili-Kakoulidou, A. Lipophilicity and biomimetic properties to support drug discovery. Expert Opin. Drug Discov. 2017, 12, 885-896. [CrossRef]

23. Igarashi, K.; Kashiwagi, K. Characteristics of cellular polyamine transport in prokaryotes and eukaryotes. Plant Physiol. Biochem. 2010, 48, 506-512. [CrossRef]

24. Redmond, J.W.; Tseng, A. High-pressure liquid chromatographic determination of putrescine, cadaverine, spermidine and spermine. J. Chromatogr. A 1979, 170, 479-481. [CrossRef] 